\title{
The long-term economic integration of resettled refugees in Canada: A comparison of Privately Sponsored Refugees and Government-Assisted Refugees
}

\author{
Lisa Kaida ${ }^{\mathrm{a}^{*}}$, Feng Hou ${ }^{\mathrm{b}}$, and Max Stick ${ }^{\mathrm{c}}$ \\ ${ }^{a}$ Department of Sociology, McMaster University, Hamilton, ON., Canada; ${ }^{b}$ Social Analysis and \\ Modelling Division, Statistics Canada, Ottawa, ON., Canada; ' Department of Sociology, \\ McMaster University, Hamilton, ON., Canada
}

*Corresponding Author: Lisa Kaida, McMaster University, 1280 Main Street West, Hamilton, ON., L8S 4M4, Canada. Email: kaidar@mcmaster.ca

Lisa Kaida is an Assistant Professor in Sociology at McMaster University. Her research specialises in immigrant and refugee integration, including immigrant poverty dynamics, gender and migration, and new immigrant destinations. Her recent work has appeared in Demography, Social Science Research, and Journal of International Migration and Integration.

Feng Hou is Principal Researcher with Social Analysis and Modelling Division, Statistics Canada. His research focuses on the socioeconomic integration of immigrants and the second generation, dynamics of social diversity, and minority-majority social interaction. He has published over 100 journal articles and book chapters in these areas.

Max Stick is a PhD student in Sociology at McMaster University. He completed his MA at Dalhousie University in Halifax, Nova Scotia, Canada. His research focuses on male immigrants' acculturation of gender norms.

Word count: 8,999 words 


\section{The long-term economic integration of resettled refugees in Canada: A comparison of Privately Sponsored Refugees and Government-Assisted Refugees}

Private refugee sponsorship has been an important Canadian policy initiative for 40 years. It is now attracting international attention as Europe grapples with an influx of refugees. However, no Canadian research has evaluated the long-term refugee economic integration associated with private sponsorship, in comparison to government assistance, using rigorous multivariate analysis. This study compares the economic outcomes of Privately Sponsored Refugees (PSRs) with those of Government-Assisted Refugees (GARs) using the Longitudinal Immigration Database, administrative data on virtually all immigrants and refugees arriving in Canada since 1980. Our regression analysis finds PSRs maintain higher employment rates and earnings than GARs up to 15 years after arrival when measurable compositional differences between the two groups are adjusted. The PSR advantage is particularly noticeable among less educated refugees. The findings suggest unmeasured factors (e.g. effectiveness of settlement policies, refugee selection processes, societal reception of refugees) may partly explain PSRs' long-term economic advantage.

Keywords: refugees; Canada; private sponsorship; economic integration; the Longitudinal Immigration Database

\section{Introduction}

The timely economic integration of refugees is a pressing policy issue for Western democracies, with refugees arriving en masse from the Middle East, West Asia and Africa. Most immigrants are accepted on the basis of economic merit, but refugees are admitted for humanitarian reasons. Many of the latter lack host country language skills and/or postsecondary education and thus struggle to achieve economic independence. As finding employment and earning an income is often perceived as the first step to full participation in the host society, refugee economic 
integration is essential from a social policy perspective (Hynie, Korn, and Tao 2016).

One refugee integration policy attracting international attention is Canada's private sponsorship. It has played a key role in the country's responses to various international refugee crises, from Southeast Asian "boat people" in 1979-1981 to recent Syrian refugees. Created in 1978, Canada's private sponsorship is a "privately funded" refugee programme (Treviranus and Casasola 2003, 181). Sponsors, such as churches, other faith groups, ethnic organisations, and groups of individuals, take in refugee applicants of their choice or refugees approved by visa officers. The sponsors are responsible for providing financial, material, and personal support to refugees during their first year in Canada or until they become self-sufficient. Although private sponsorship is one of the two main refugee resettlement programmes (the other is government assistance) and anecdotes of its success abound, quantitative research on the economic advantage of Privately Sponsored Refugees over Government-Assisted Refugees is limited (Beirens and Ahad 2018; Kumin 2015). Nor do we know if it differs according to the refugees' initial levels of human capital. As several European nations (e.g. Germany, France, the UK) are implementing or piloting private sponsorship and the European Union is exploring its roles to promote private sponsorship across its member nations, a rigorous assessment of Canada's long-standing sponsorship programme will be of interest to researchers and policy makers beyond Canada (European Commission 2018; Fratzke and Beirens 2018).

This paper evaluates the short- and long-term economic outcomes of resettled refugees from two programmes, private sponsorship and government assistance, with various human capital levels. We have two main research questions. First, are the economic advantages of Privately Sponsored Refugees over Government-Assisted Refugees limited to the initial period of resettlement? Or do they extend into a long-term resettlement process? Second, does the 
labour market advantage of Privately Sponsored Refugees vary by the initial levels of human capital (official language skills and education) of refugees? We answer these questions by drawing on the Longitudinal Immigration Database (IMDB), administrative data containing the landing and annual tax records of virtually all immigrants/refugees arriving in Canada after 1980.

This paper makes three contributions to the literature. First, by using multivariate analysis, we compare the economic outcomes of Privately Sponsored Refugees (PSRs) with those of Government-Assisted Refugees (GARs) while controlling for the differences in their measurable demographic, socioeconomic, and contextual characteristics. This allows us to better examine the differences in refugee economic integration by admission categories than the previous research, which mostly uses simple bivariate analysis.

Second, this is the first study to examine the interaction effect of admission categories (PSR vs GAR) by refugees' initial human capital. It considers the reality that refugees are a heterogeneous population, with varying degrees of educational attainment and host country language skills at the time of arrival. Programmes like private sponsorship and government assistance may facilitate economic integration differently depending on refugees' initial human capital level. Policies can potentially be tailored to target sub-groups of refugees who would benefit more from private sponsorship or government assistance to achieve their economic mobility quickly.

Third, the study makes a timely contribution to refugee integration policy internationally, as a number of Western nations are grappling with the sudden need to integrate tens of thousands of refugees, considering private sponsorship programmes as a viable strategy for economic integration. By providing empirical evidence of the economic outcomes of private sponsorship in 
Canada, the forerunner of such resettlement policy, the study will help policy makers make informed decision on refugee integration.

\section{An Overview of Refugee Economic Integration}

It is widely acknowledged that refugees do less well in the host country labour market than those who immigrate through other streams like economic immigration (Bevelander 2016; Constant and Zimmermann 2005a, 2005b). Whilst some of the factors contributing to the labour market disadvantage of refugees apply to other immigrants (e.g. limited host country language skills, lack of host country work experience, non-recognition of foreign credentials), others are specific to refugees, such as physical and mental health issues related to traumatic experiences of displacement and life in refugee camps, the lack of legal documents, and long-term disruptions in education and career (Bruno 2011; Hynie, Korn, and Tao 2016; Krahn et al. 2000; Neupane 2012; van Selm 2003).

In Canada, the main findings on refugee economic integration are threefold. First, refugees fare less well during the initial resettlement period than economic immigrants, who are admitted to Canada based on their human capital (e.g. education, language skills, occupations), but refugees' economic outcomes are comparable to those of family class immigrants admitted for family reunification (Aydemir 2011; Bevelander and Pendakur 2014; Hiebert 2009; Hyndman 2011; Yu and Dempsey 2004).

Second, despite their initial disadvantage, refugees quickly catch up with other immigrants. An analysis of immigrants landing in Canada in 1982, 1988, and 1994 by Abbot and Beach (2011) finds refugee men and women achieve $7-11 \%$ and $8-12 \%$ growths in median annual earnings, respectively, within the first 10 years in Canada - the highest growth rate of all 
admission categories. That said, however, refugees' initial disadvantage is so large that it takes them more than 12-18 years to reach the median earnings of all immigrants.

Third, both refugee women and men face an uphill battle in economic mobility, but the extent of the disadvantage varies, depending on economic measures and comparison groups. In his analysis of immigrants who landed in Vancouver between 1989 and 2004, Hiebert (2009) finds the employment rate of refugee men in 2005 is comparable to that of family class immigrant men (65\%) but much lower than that of skilled worker immigrants (75\%). In contrast, refugee women are much more likely to earn an employment income (62\%) than their family class counterparts (56\%). By the same token, Wilkinson and Garcea (2017) demonstrate refugee women are less likely to hold temporary jobs than family immigrants (23\% and $29 \%$, respectively), whereas refugee men are more likely to do so than their family class comparators (25\% and $19 \%$, respectively).

We are not alone in choosing to analyse the IMDB data, but our focus is on the heterogeneity within refugees by admission category (Abbott and Beach 2011; Dhital 2015; Hiebert 2009; Mata and Pendakur 2017). In addition, rather than limiting the study to a specific entry cohort and tracking the outcomes of only the first few years in Canada, we include all cohorts arriving between 1980 and 2009 and trace their outcomes up to 2015. This allows us to estimate economic outcomes for up to 15 years.

\section{An Advantage of Privately Sponsored Refugees?}

While the relative economic disadvantage of refugees is well known, little research has explored the within-group differences in refugee economic outcomes, especially between different admission categories. We focus on two longstanding refugee categories in Canada, Privately Sponsored Refugees (PSRs) and Government-Assisted Refugees (GARs), and asks whether 
PSRs fare better than GARs, as suggested by previous research.

Although the private sponsorship of refugees had been ongoing for many years, the Immigration Act formally ushered in Canada's private sponsorship in 1978 (Macklin et al. 2018). This programme increased the number of refugees who could be admitted to Canada, offsetting government budgetary constraints by harnessing the private resources of citizens and groups. It allowed Canadians to get involved in the resettlement process by volunteering their financial and emotional support (Lenard 2016). Sponsors are restricted to groups of five or more people, organisations, or sponsorship agreement holders, particularly religious groups (Lanphier 2003). The private sponsorship programme is now a vital component of Canada's refugee policy, resettling over 225,000 refugees since 1979 (Labman 2016).

Although limited in scope, empirical evidence on the economic integration of PSRs suggests these refugees achieve "slightly quicker self-sufficiency" than GARs, finding employment more quickly and earning more during the first 10 years in Canada (Wilkinson and Garcea 2017, 17). PSRs' employment rates are higher during the very initial resettlement stage. An analysis of refugees admitted to Canada between 2002 and 2012 shows only 40\% of GARs have employment one year after arrival, compared to $70 \%$ of PSRs (IRCC 2016). The PSR-GAR gap shrinks over time, and by year 10, the employment rates almost converge, $58 \%$ for PSRs and $54 \%$ for GARs.

Other studies demonstrate PSRs' higher earnings/incomes than GARs for up to the first seven years in Canada (Beiser 2003; Bevelander and Pendakur 2014; DeVoretz, Pivnenko, and Beiser 2004; Mata and Pendakur 2017; Sweetman and Warman 2013; Yu and Dempsey 2004). Whether this advantage persists in the longer term is unclear, however, and findings are mixed. Immigration, Refugees and Citizenship Canada's analysis of the Longitudinal Immigration 
Database finds the gaps in employment earnings between the PSRs and GARs arriving between 2002 and 2012 diminish after the 10-year mark (IRCC 2016). At this point, the mean employment earnings of PSRs and GARs are $\$ 33,000$ and $\$ 32,000$, respectively. In contrast, an analysis of the IMDB data (aggregated by age, birthplace, and landing year) by Mata and Pendakur (2017) finds while both PSRs and GARs start with notably lower earnings than economic and family class immigrants, PSRs experience steeper earnings growths than GARs. By the $19^{\text {th }}$ year in Canada, PSR men and women are estimated to have annual earnings of $\$ 62,000$ and $\$ 45,000$, respectively - several thousand dollars higher than their GAR counterparts.

Despite such generally positive evidence and the growing international recognition of Canada's private sponsorship as a "shining example" of community-based refugee resettlement, multivariate analysis on the economic outcomes of PSRs using individual-level data is limited (Fratzke 2017, 1). Most assessments use simple descriptive statistics for a shorter period of resettlement. These high-level overviews do not fully consider the differences between PSRs and GARs in human capital or demographic and contextual characteristics (Jedwab 2018). While our study uses the IMDB like the aforementioned studies, it improves upon them by conducting multivariate analysis of its individual-level records (Abott and Beach; 2011; Dhital 2015; IRCC 2016; Mata and Pendakur 2017). This allows us to track individual refugees' economic outcomes longitudinally while controlling for a number of measurable characteristics.

In comparing the outcomes of PSRs and GARs, we adopt an emerging theoretical perspective that the migration type is a key source of inequality, contributing to divergent patterns of immigrant incorporation (Vertovec 2007). This perspective posits immigrants in different admission categories move to a new country with "different motivation for migration, pre-migration circumstances, selection process, legal status, and host country receptivity" (Hou 
and Bonikowska 2016, 1453) In this regard, the motivations of PSRs and GARs are similar; both are forced out of the home country by war, political persecution, or violence; they are seeking protection and a safe space to rebuild their lives in Canada. They also have the same legal status in that they are granted permanent resident status upon arrival in Canada (European Commission 2018).

Yet, PSRs and GARs may differ in other characteristics related to pre-migration circumstances, selection processes, and host country receptivity, and these may partially account for their divergent trajectories of economic integration. Using the IMDB data, we are able to consider differences in measurable characteristics related to host country receptivity, as well as differences in human capital and migration-related characteristics.

As a result of different resettlement policies, PSRs and GARs may be in different economic contexts of reception, and these may influence their economic integration. GARs tend to live outside the three immigrant gateway cities (Toronto, Montreal, and Vancouver), settling in secondary cities which are part of the designated communities. Over there, they are entitled to receive the Resettlement Assistant Program (RAP) services (CIC 2011). In contrast, PSRs are more likely to settle in the three gateway cities, even though individuals or organisations across the country can volunteer to sponsor government-approved refugees or refugees of their choice. Although some refugees quickly leave the initial destination, variations in the geographic distributions of PSRs and GARs persist. An analysis of the 2016 Census data by Jedwab (2018) finds $60 \%$ of PSRs who arrived in Canada after 1980 live in Toronto, Montreal, and Vancouver, compared to only $43 \%$ of GARs. The larger gateway cities tend to have more economic opportunities than smaller non-gateway cities, where the local economy is often stagnant. Thus, PSRs may be more likely to live in a place with lower unemployment rates than GARs. 
Variations in human capital profiles of PSRs and GARs may also partially account for their divergent economic integration. Studies show among refugees from a specific entry cohort, GARs tend to have lower education than PSRs (Houle 2019; IRCC 2016). For example, while 17\% of PSRs who arrived in Canada between 2011 and 2016 have some postsecondary degrees, only nine percent of GARs do so (Jedwab 2018). With higher education, PSRs may be more likely to return to school and upgrade their skills in the host country, and this may partially account for their economic advantage. Moreover, PSRs generally possess higher host country language skills. Among the refugees who arrived in Canada between 2011 and 2016, 38\% of PSRs knew English or French at the time of landing, 12 percentage points higher than their GAR counterparts (IRCC 2016).

Further, PSRs and GARs vary in their migration-related characteristics, such as birth region, age at migration, and period of migration, and these may have an impact on their divergent economic outcomes (Levitz 2016; Picot, Zhang, and Hou 2019). Jedwab (2018) finds those from Africa and the Americas are overrepresented among the GARs arriving in Canada between 1980 and 2016 compared to their PSR counterparts. Conversely, the proportion of PSRs from Asia and Europe is higher than that of GARs from these regions.

Admittedly, these contextual, human capital, and migration-related characteristics are far from a complete list of variables that can account for differences in economic outcomes. Unmeasured differences in pre-migration circumstances (e.g. experience in refugee camps, length of dislocation), selection process (e.g. measurement of "vulnerability" in GAR selection), receptivity (e.g. welcoming or unwelcoming community), and other characteristics (e.g. health) may contribute as well. 
We also consider the possibility of interaction effects of refugee admission category and human capital, as refugees are a socioeconomically diverse group (Houle 2019; IRCC 2016; Jedwab 2018; Picot, Zhang and Hou 2019). On the one hand, refugees with high human capital (e.g. highly educated, proficient in English/French) may be more self-sufficient and able to achieve economic success with little sponsor support (Nakhaie 2018). On the other hand, refugees with limited human capital may take greater advantage from private sponsorship, as their deficit in human capital can be compensated for by the support from their sponsors. If we observe differential economic advantage of private sponsorship based on refugees' human capital, the current private sponsorship programme, which does not take refugees' human capital into account, could be revised to prioritise the sponsoring of refugees with little education and limited English/French skills.

Based on the above discussion, we derive three hypotheses and test them using the IMDB data.

- Hypothesis 1: Privately Sponsored Refugees are more likely to be employed and earn more than Government-Assisted Refugees both in the short term (less than five years) and the long term (15 years) when their demographic, socioeconomic, and contextual characteristics are controlled.

- Hypothesis 2: The employment and earnings advantages of Privately Sponsored Refugees over Government-Assisted Refugees are greater for less educated refugees (e.g. less than high school) than more educated refugees (e.g. bachelor's or above degrees). 
- Hypothesis 3: The employment and earnings advantages of Privately Sponsored Refugees over Government-Assisted Refugees are greater for those with limited host country language skills than those with higher host country language skills.

\section{Data/Methods}

\section{Data}

We analyse the Longitudinal Immigration Database (IMDB), which contains landing records and annual tax records of immigrants who arrived in Canada in 1980 and onward. Those who filed taxes at least once since 1982 are included. The IMDB is virtually a $100 \%$ sample of immigrants who landed over the past 35 years and filed taxes in Canada (Hou and Bonikowska 2016).

The study sample consists of individuals who landed in Canada as Privately Sponsored Refugees (PSRs) or Government-Assisted Refugees (GARs) at age 20-54 between 1980 and 2009. Other categories of refugees (e.g. in-Canada asylum seekers, refugee dependents, Blended Visa Office-Referred refugees) are not included because of small sample sizes and stark differences in characteristics which would make the comparison difficult. PSRs and GARs from the US, Northern/Western Europe, and Oceania (e.g. Australia, New Zealand) and stateless individuals are also excluded because of small sample sizes.

\section{Measures}

We use two dependent variables to study the economic integration of refugees: 1) employment; and 2) employment earnings in a specific year since landing. Employment is an indicator of "self-sufficiency or [..] steps that will lead to gainful work" (Beiser 2003, 209). As the direct measure of employment status is unavailable in the IMDB data, we consider an annual 
employment income (including wages, salaries, and self-employment incomes) over $\$ 1,000$ in a specific tax year as employment in that year (coded 1). Those with employment income below $\$ 1,000$ or with no employment income are coded 0 . The earnings reflect the combined effect of total hours of work in a particular year and hourly wages (Hou and Bonikowska 2016). We select this variable because better paying employment may allow refugees to participate more fully in the host society (Hynie, Korn, and Tao 2016). This is a continuous variable adjusted to the 2015 Consumer Price Index but is top coded at $\$ 300,000 \mathrm{CDN}$ to prevent the higher income values from skewing the distribution. For our multivariate analysis, we use logged earnings values.

The first focal independent variable is the refugee admission category, with two groups, Privately Sponsored Refugees and Government-Assisted Refugees (the reference group). The second independent variable is years since landing (YSL). The first two years are treated as dummy variables, and years three and onward are coded as a continuous variable. We do so because previous studies find notable differences in employment and earnings between GARs and PSRs in the first two years after arrival (IRCC 2016; Mata and Pendakur 2017). Our descriptive statistics (Figures 1 and 2) confirm the differences between PSRs and GARs in employment and earnings are large in year 1 , shrink in year 2, and remain stable or gradually decrease thereafter. Note that treating the YSL variable as a linear (and quadratic) term does not adequately fit the observed employment and earnings trajectories of refugees. Our analysis shows the R-squared of a model which controls for years 1 and 2 dummies, a linear YSL term (for year 3 and onward), and its quadratic term is consistently higher than the R-squared of a model where the YSL is treated as a continuous variable from year 1 and onward (results are available upon request).

[Figures 1 and 2 about here] 
We also control for refugees' human capital characteristics at the time of landing: the highest level of education obtained before landing (less than high school, high school diploma/trade certificate, some post-secondary education, bachelor's or higher degree); and knowledge of official languages (English and/or French; neither English nor French). As detailed in the Analytical Technique, these are included as main effects in regression models to test Hypothesis 1 (examining the economic advantage of PSRs over time). In testing Hypotheses 2 and 3 (examining the economic advantage of PSRs by level of human capital), we interact the human capital variables with YSL and refugee admission category.

Moreover, we include, as control variables, demographic characteristics at the time of landing that are expected to influence subsequent economic outcomes: age at landing $(20-29 ; 30$ 39; 40-49; 50-54); region of origin (South and Central America and Caribbean; Eastern Europe; Southern Europe; Africa; Middle East and West and Central Asia; Southeast Asia; other Asia); and entry cohort (landed in 1980-1984;1985-1989; 1990-1994; 1995-1999; 2000-2004; 20052009). ${ }^{1,2}$

Further, we introduce three time-varying control variables: place of residence (Montreal; Vancouver; Toronto; medium-sized Census Metropolitan Areas, other small Census Metropolitan Areas; small urban or rural areas; no place information); unemployment rates (for men aged 25-64) in the refugee's province of residence in a specific tax year; and the number of months in school during a specific year as a full-time student. The values of these variables can vary in each year.

\section{Analytical Technique}

We adopt Ordinary Least Square (OLS) regression models to examine whether the economic 
advantage of Privately Sponsored Refugees over Government-Assisted Refugees persists after controlling for the length of residence in Canada. To test Hypothesis 1, we estimate the following model:

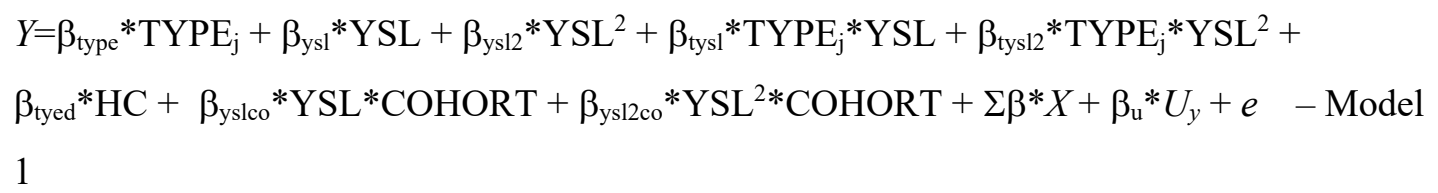

$Y$ signifies the dependent variable, employment status or earnings. Since the employment status variable is dichotomous, we adopt linear probability models, treating the variable as continuous. We choose the linear probability model over the logistic regression model, as the interaction effects in logistic models cannot be easily interpreted (Picot and Hou 2011). Results from these two models are similar in their coefficients and statistical significance.

YSL indicates years since landing (including years 1 and 2 dummies and a linear term for year 3 and onward). The TYPE $\mathrm{j}_{\mathrm{j}}$ variable represents the refugee admission category, and $\mathrm{HC}$ refers to the human capital variables of the highest level of education and knowledge of official languages. One of the control variables, period of landing in Canada (COHORT), is interacted with YSL because refugees' economic outcomes may vary by entry cohort (Picot, Zhang, and Hou 2019). This is a common approach in regression models predicting immigrant economic outcomes. Finally, $X$ represents other individual-level control variables (e.g. age at landing, region of origin, place of residence), and $U_{\mathrm{y}}$ stands for the time-varying variables of regional unemployment rates, number of months in full-time schooling, and place of residence.

To test Hypotheses 2 and 3 (examining the varied economic advantage of PSRs by level of human capital), we include a three-way interaction among refugee admission categories, YSL, 
and the highest level of education (for Hypothesis 2) and among admission categories, YSL, and the knowledge of official languages (for Hypothesis 3).

$$
\begin{aligned}
& Y=\beta_{\mathrm{type}} * \mathrm{TYPE}_{\mathrm{j}}+\beta_{\mathrm{ysl}} * \mathrm{YSL}+\beta_{\mathrm{ysl} 2} * \mathrm{YSL}^{2}+\beta_{\mathrm{tyed}} * \mathrm{HC}+\beta_{\mathrm{tysl}} * \mathrm{TYPE}_{\mathrm{j}} * \mathrm{YSL}+ \\
& \beta_{\mathrm{tysl} 2} * \mathrm{TYPE}_{\mathrm{j}} * \mathrm{YSL}^{2}+\beta_{\mathrm{hcsl}} * \mathrm{HC} * \mathrm{YSL}+\beta_{\mathrm{hcsl} 2} * \mathrm{HC}^{*} \mathrm{YSL}^{2}+ \\
& \beta_{\mathrm{tyhc}} * \mathrm{TYPE}_{\mathrm{j}} * \mathrm{HC}+\beta_{\mathrm{hctysl}} * \mathrm{HC}^{*} \mathrm{TYPE}_{\mathrm{j}} * \mathrm{YSL}+\beta_{\mathrm{hctys} 2} * \mathrm{HC}^{*} \mathrm{TYPE}_{\mathrm{j}} * \mathrm{YSL}^{2}+ \\
& \beta_{\mathrm{yslco}} * \mathrm{YSL}^{*} \mathrm{COHORT}+\beta_{\mathrm{ys} 2 \mathrm{co}} * \mathrm{YSL}^{2} * \mathrm{COHORT}+\Sigma \beta^{*} X+\beta_{\mathrm{u}} * U_{y}+e-\operatorname{Model} 2
\end{aligned}
$$

As the above equation shows, to Model 1, we add two-way interaction terms between human capital and refugee admission categories, human capital and YSL and three-way interaction terms among human capital, admission categories, and YSL.

All the models are run separately for refugee women and men. We calculate clusterrobust standard errors for the regression models to consider the clustering of data at province (for the unemployment rate variable) and year (for refugee person-year data) levels. The use of robust standard errors allows us to correct for autocorrelation of repeated observations of the same immigrant. For our employment analysis (those with an annual employment income of $\$ 1,000$ or more in a specific tax year are considered employed), the person-year data yield 3,345,239 cases for men and 2,468,735 cases for women. The comparable numbers for the earnings analysis (limited to the employed) are 2,637,550 and 1,565,625 for men and women, respectively.

\section{Results}

\section{A first look}

We begin our analysis with the observed employment and earnings outcomes in each refugee admission category for men and women. Figure 1 displays the employment rates (mean probabilities of employment) of PSR and GAR women and men by each year since landing. 
Figure 1 also includes the outcomes of economic immigrants to put the results of the two resettled refugee groups in perspective. Economic immigrants constitute the largest admission category in Canada, selected on the basis of their economic contribution to the country (Evra and Prokopenko 2018).

We observe the higher employment rates of PSRs ( $89 \%$ and $69 \%$ for men and women, respectively) in the first year after landing - 19 and 25 percentage points higher than their GAR comparators, for men and women, respectively. These rates are even higher than those of economic immigrants ( $80 \%$ and $61 \%$ for men and women, respectively, in year 1). PSRs' employment rates drop in the next two years but remain high. After the initial drop, PSR men's employment rates hover around $80 \%$ throughout their first 15 years, maintaining higher employment rates than GARs and economic immigrants. Meanwhile, PSR women's employment rates slightly drop to $64 \%$, then incrementally rise over time. In the long term, their employment rates are lower than those of their economic immigrant counterparts. Overall, PSRs have unique employment trajectories, deviating from the general pattern of immigrants, whose employment rates tend to be low upon landing and rise over time (Chui and Tran 2003).

The considerable drop in the employment rate of PSRs can be explained in several ways. Some jobs they find with the sponsor's help may be short-term and end when the sponsor's formal commitment ends. Some PSRs may take up jobs simply to satisfy the sponsor and become self-sufficient as quickly as possible, but they might dislike the work and quit soon after the sponsorship commitment is over. Thus, PSRs' high employment rates may reflect private sponsors' high expectations of economic independence before the agreement ends, typically 12 months after arrival. Ending the sponsorship in a year may release sponsorship funds for the next wave of refugees, and these may be family members or relatives left behind in a refugee camp or 
home country, making early employment a priority. ${ }^{3}$

Nor is the very low employment rate of GARs in the first year all that surprising. During this time, GARs receive income assistance from government, allowing them to improve their official language skills. As such, their priority may be on improving host country language, rather than finding employment. After the first two years, however, GARs, especially women, rapidly catch up with PSRs. The initial PSR-GAR gap among women steadily decreases throughout the first 15 years. For men, the gap stabilises at around four to five percentage points until year 14. Overall, PSRs' higher employment persists for a long time.

Figure 2 shows mean annual earnings for PSRs, GARs, and economic immigrants by gender in years 1-15 after landing. The earnings of the two resettled refugee groups are much lower than those of economic immigrants throughout the first 15 years in Canada. However, the observed earnings steadily rise for both PSRs and GARs each year, a sign of upward economic mobility. The PSRs' earnings advantage quickly stabilises at around $\$ 2,000$ and $\$ 1,000$ for men and women, respectively. Even though their advantage fluctuates over time, PSRs earn more than GARs throughout the first 15 years.

The results from Figures 1 and 2 are observed outcomes, without adjusting for the differences in the measurable characteristics between PSRs and GARs. However, as Table 1 demonstrates, there are some stark differences. First, those from Eastern Europe (especially Poland) are overrepresented among PSRs (43\% and 39\% of men and women, respectively), whereas the percentage of refugees from South and Central America and Caribbean is notably high among GARs (over 10\%). ${ }^{4}$ Second, those with less than high school education are overrepresented among GARs (53\% and 65\% for men and women, respectively). Third, PSRs are concentrated in the 1985-1994 cohort (comprising 62\% and 57\% of all PSR men and women, 
respectively), but the GARs' arrival periods are evenly distributed. Finally, 40\% of PSRs initially settled in Toronto, whereas comparable percentages of GARs went to smaller metropolitan areas (e.g. Ottawa, Calgary). These group differences in demographic and socioeconomic characteristics may partially explain the higher employment and earnings of PSRs. In the next section, we use multivariate analysis to test this possibility.

[Table 1 about here]

\section{Short- and long-term economic outcomes of GARs and PSRs}

We run OLS regression models predicting employment (Appendix Table A1) and earnings (Table A2) adjusting for group differences in characteristics at the time of landing, including age at arrival, region of birth, period of landing, level of education, and knowledge of official languages, and in characteristics after arrival, including unemployment rates of the province of residence, number of months in full-time schooling, and geographic location of residence in a specific year (Model 1). The goal is to determine whether the PSRs' long-term advantage in employment and earnings will remain when the differences in their observed characteristics are held constant.

[Appendix Tables A1 and A2 about here]

To report the regression results in a simple way, we estimate the probabilities of employment and earnings for PSRs and GARs from year 1 to 15, holding constant the values of the control variables in Model 1 in Appendix Tables A1 and A2 (using the sample means for continuous variables and proportional distributions for categorical variables). We then calculate the differences between PSRs and GARs in the estimated outcome values (employment and logged earnings) and plot the values. Figures 3 and 4 display the estimated differences for 
employment (Figure 3) and earnings (Figure 4) from year 1 to 15 for men and women.

[Figures 3-4 about here]

As Figure 3 shows, PSRs' employment advantage lasts for a long time for both men and women. Although it rapidly diminishes during the initial settlement period (years 1-3), it remains statistically significant up to 15 years after landing $(p<.05)$, lending support to the argument that PSRs maintain long-term advantage over GARs in employment. ${ }^{5}$

Similar patterns hold for the earnings of PSRs and GARs. As Figure 4 demonstrates, the estimated difference between PSRs and GARs in logged earnings is positive throughout the first 15 years since landing, so PSRs consistently earn more than GARs. By the 15 th year in Canada, PSRs' estimated earnings are 0.05 and 0.04 log points higher than GARs' earnings for men and women, respectively $(p<.05)$.

\section{Does the PSR advantage vary by refugees' initial human capital?}

Next, we examine whether the economic advantage of PSRs varies by refugees' initial human capital, measured by the level of education and knowledge of official languages. To Model 1, we add two-way interaction terms between admission categories and human capital, and human capital and years since landing (YSL), as well as three-way interaction terms among admission categories, human capital, and YSL, and estimate the probability of employment (Model 2, Table A1) and earnings (Model 2, Table A2). We report the results using graphs of estimated advantage/disadvantage of PSRs over GARs by education level (Figures 5-8). Comparable results for the knowledge of official languages are available upon request.

[Figures 5-8 about here] 
The results show the employment advantage of PSR men over GAR men with a lower level of education is greater in the long term than that of PSR men with bachelor's degree or above (Figure 5). Although their employment advantage decreases quickly during the first three years in Canada, it does remain throughout the first 15 years. In year 15, their estimated probability of employment is still three percentage points higher than their GAR counterparts $(p$ $<.05)$. In contrast, the employment advantage of better educated PSRs over GARs is much smaller and lasts for a shorter time. For instance, the advantage of PSRs with some postsecondary education over their GAR counterparts is below five percentage points by year 5 .

Overall, the results for refugee women are similar to men, in that the employment advantage of PSR women with less education over GAR women is noticeable, but there is less difference between GAR and PSR women with high school diplomas/trade certificates, some postsecondary education, and bachelor's or above degrees (Figure 6). Only PSR women without high school education have higher employment rates than their GAR comparators for as long as 15 years after landing $(p<.05)$. Meanwhile, the PSR-GAR difference in employment becomes non-significant (at $p=.05$ level) in year 14, 13, and 11 for those with high school diplomas, some postsecondary education, and bachelor's or higher degrees, respectively.

When the earnings of refugees with different levels of initial education are estimated, the results for earnings are mostly the same as those for employment; PSRs without high school education have the greatest advantage over their GAR counterparts throughout the whole 15 years in Canada (Figures 7 and 8). In fact, the earnings advantage of the more educated PSRs is no longer statistically significant by years $3-8(p>.05)$.

The employment advantage of PSRs over GARs varies little by official language ability when at-landing demographic and socioeconomic characteristics and post-migration 
characteristics are adjusted. PSRs are more likely to be employed than GARs, and their employment advantage persists up to 15 years, whether or not they know English and/or French at arrival. Contrary to our expectations, the employment advantage of PSR men without initial knowledge of English and/or French over their GAR counterparts is greater than that of PSR men who knew English and/or French at arrival in the first two years in Canada. The advantages of PSR men with and without knowledge of official languages are almost the same in year 3 and onward. For refugee women, those without knowledge of English or French have a slightly greater advantage over GARs than those who know English and/or French at arrival (a 24 and 22 percentage point advantage, respectively), but the advantage reverses in year 2 and onward. PSRs who know English and/or French have greater employment advantage between years 3 and 10, but after year 10, the advantage virtually disappears for both language groups.

When the refugees' earnings are estimated, men and women follow fairly similar patterns. The earnings advantage of PSRs who know neither English nor French over their GAR counterparts is slightly greater than that of PSRs who know English and/or French at arrival (0.1 $\log$ point), but it quickly diminishes. In the long term, the earnings advantage of PSRs with initial knowledge of English and/or French surpasses that of PSRs without initial knowledge of official languages.

\section{Conclusions and Discussion}

In this paper, we compare the short- and long-term employment and earnings outcomes of Privately Sponsored Refugees (PSRs) and Government-Assisted Refugees (GARs) admitted to Canada between 1980 and 2009. The use of the Longitudinal Immigration Database (IMDB) allows us to estimate these outcomes up to 15 years after landing whilst controlling for group differences in demographic and socioeconomic characteristics at the time of landing, along with 
some post-migration characteristics.

Our multivariate analysis of the probability of employment and the earnings of refugees demonstrates PSRs have an initial advantage and retain this for the first 15 years. Therefore, Hypothesis 1 is supported: even when we hold constant the differences in measurable characteristics between the two refugee streams, PSRs are more likely to be employed and earn more than their GAR counterparts. Of course, other factors related to pre-migration characteristics, selection processes, and host country reception could account for the difference. For example, unmeasured pre-migration characteristics (e.g. health, experience in refugee camps, duration of displacement) may be associated with the selection criteria of the governmentassisted refugee programme. Therefore, GARs may face more challenges in resettlement, including finding paid work, due to physical/mental health issues related to an extended period of displacement or to disrupted education and career because of prolonged time in refugee camps (Oda et al. 2018). Unfortunately, the data on such pre-migration characteristics are unavailable in the IMDB.

Contexts of the host country community surrounding refugees may matter as well. PSRs may benefit from sponsors' social and community support, not only within the first year of required sponsor commitment, but over the long term. Even though the sponsor's initial support officially ends one year after arrival, the benefits may be long-lasting, with some refugees maintaining extended ties with sponsors (Woon 1987). In addition, some ethnic communities may selectively sponsor co-ethnic refugees (including family members displaced abroad); these sponsored refugees may take advantage of the pre-existing ethnic and family networks and receive more culturally sensitive resettlement support (Portes and Rumbaut 2001). Such favourable environments may help PSRs find jobs more quickly. 
Our analysis also supports Hypothesis 2: the long-term employment and earnings advantage of those who are privately sponsored over those receiving government assistance is greater for refugees with less education than more education. Interestingly, more educated PSR women with high school diplomas or trade certificates, some postsecondary education, or a bachelor's or above degree do not enjoy the ongoing economic advantage of their fellow PSRs without high school education. The employment and earnings advantages of the more educated PSR women quickly lose statistical significance, and the well-educated GAR women catch up to them three to eight years after landing. In other words, only the least educated PSR women fare better than their GAR counterparts in the long run. Since the majority of refugees have less than high school education (51\% and $61 \%$ of men and women, respectively, in the sample), this finding has significant policy implications. Private sponsorship seems to have far-reaching, longterm advantage for a large segment of this disadvantaged group, especially women. Meanwhile, the minimal and short-term advantage of PSR women with more education may reflect the double disadvantage of skilled immigrant women associated with gender and immigrant status (i.e. internationally-trained) in the host country labour market (Creese and Wiebe 2012). The high-skill service sector jobs (e.g. health care, education) to which these more educated PSR women may aspire require re-accreditation or skill upgrading, something beyond the reach of sponsors' short-term support. In contrast, educated PSR men may be more likely to find highskill jobs in manufacturing through sponsors' local networks.

Hypothesis 3 speculates that the employment and earnings advantage of PSRs will be greater for those with limited host country language skills than those with more advanced language skills. This hypothesis is rejected for both refugee men and women in employment and earnings. PSRs without initial knowledge of English and/or French have no long-term 
employment and earnings advantage over those who know English and/or French at the time of landing. It may be that PSRs are acquiring official language skills quickly through interactions with their sponsors during the initial settlement period, thus overcoming the language barrier (Woon 1987). In addition to improving their host country language skills, they may also be expanding their networks with the native-born mainstream group, making them no different in employment and earnings from those who know English and/or French upon arrival. That being said, we find PSRs who know English and/or French have a greater advantage in employment and earnings than their non-English/French speaking PSR counterparts in the long term. These linguistically advantaged refugees may be more likely to maintain contacts and friendships with sponsors, taking advantage of the social capital developed through these long-lasting relationships (Woon 1987).

Our study contributes to the ongoing international policy debate on refugee resettlement strategies by illuminating the economic advantages of Privately Sponsored Refugees in the long term. Only recently, particularly in the wake of the 2015 migration crisis, has private sponsorship gained prominence outside Canada. Even then, other programmes fall short of the Canadian model. For example, sponsorship programmes in France and Australia have more bureaucratic structures, as resources are allocated through central distribution centres with specialised workers providing service in lieu of volunteers (Kumin 2015). Another key difference is that some programmes, such as those of Australia, the UK, and Portugal, are designed to supplement, rather than exceed, government refugee quotas (Fratzke 2017). Some even limit the intake of refugees to certain nationalities. For instance, Germany’s programme only sponsors Syrian refugees and grants temporary residence with the possibility of renewal (Kumin 2015). Other programmes, such as in the US, are for shorter periods and depend more on welfare subsidies 
(Lanphier 2003). Canada's private sponsorship seems unique (Hyndman, Payne, and Jimenez

2017; Labman 2016; Lanphier 2003). Even though the main goal of refugee acceptance is not to boost the national economy but to meet humanitarian needs, the current private sponsorship programme in Canada facilitates both the short- and long-term economic integration of refugees.

\section{Notes}

1. We did not control for years of work experience, a variable often included in the analysis of immigrant economic outcomes. There is no direct measure of work experience in the IMDB, and its common proxy measure (age - years of schooling - 5 or 6 ) is inappropriate for our study. As refugees often spend years in refugee camps, their paid work experience can be disrupted (Korn and Raphael 2016).

2. Selection criteria for GARs changed in 2002 with implementation of the Immigration and Refugee Protection Act (IRPA), putting more emphasis on the protection of vulnerable refugees. As a result, GARs who arrived in 2002 and after are considered to have greater difficulty adapting to their new lives in Canada than the earlier arrivals (IRCC 2016). We conducted a sensitivity analysis on the sample of refugees excluding the post-2001 arrivals and compared the results with those of our original sample. It showed a smaller gap in employment rates and earnings between GARs and PSRs for the 1980-2001 cohort in years 1-2 than in the original sample. This suggests the employment rates and earnings of the post-IRPA GARs may be lower in the first two years in Canada. However, the GAR-PSR gaps are broadly similar for the 1980-2001 and 1980-2009 cohorts after year 2. This leads us to conclude that our analysis of the long-term economic outcomes of PSRs versus GARs would not be influenced by the choice of arrival cohorts.

3. We thank an anonymous reviewer for an insightful interpretation of the year 1 results.

4. Considering the advantageous economic standing of refugees from Poland, we conducted a sensitivity analysis of the sample of refugees excluding those from Poland and compared the results with those 
for our original sample which includes Polish refugees (Picot, Zhang, and Hou 2019). Results from these two samples were virtually the same.

5. We conducted a statistical significance test on the differences in estimated probabilities of employment and earnings between PSRs and GARs in each YSL using STATA 15's margins function. The results are available upon request.

\section{Acknowledgments}

Earlier versions of this paper were presented in the Quebec Inter-university Centre for Social Statistics (QICSS) International Conference in Montreal, October 11-12, 2018, the National Metropolis Conference in Halifax, March 21-23, 2019, and the annual meeting of the Population Association of America in Austin, April 11-13, 2019. The authors thank Cynthia Buckley, Lori Wilkinson, Yoko Yoshida, JEMS' anonymous reviewers, and a deputy editor for their helpful comments. Thanks also go to Elizabeth Thompson for her editorial support. The analysis presented in this paper was conducted at the McMaster University Research Data Centre, part of the Canadian Research Data Centre Network (CRDCN). The services and activities provided by the McMaster RDC are made possible by the financial or in-kind support of the SSHRC, the CIHR, the CFI, Statistics Canada, and McMaster University. The views expressed in this paper do not necessarily represent those of the CRDCN or its partners.

\section{Disclosure of Interest}

The authors report no conflict of interest.

\section{Funding}

This research was supported by the Social Sciences and Humanities Research Council of Canada under the Insight Grant, awarded to the first and second authors (grant no. 435-949-2018).

\section{References}

Abbott, Michael, and Charles Beach. 2011. Do Admission Criteria and Economic Recessions Affect Immigrant Earnings? IRPP Study 22. Montreal: Institute for Research on Public 
Policy. http://irpp.org/wp-content/uploads/assets/research/diversity-immigration-andintegration/new-research-article/IRPP-Study-no22.pdf

Aydemir, Abdurrahman. 2011. "Immigrant Selection and Short-Term Labor Market Outcomes by Visa Category." Journal of Population Economics 24 (2): 451-475.

Beirens, Hanne, and Aliyyah Ahad. 2018. Scaling Up Refugee Resettlement in Europe: The Role of Institutional Peer Support. Brussels: Migration Policy Institute Europe. https://www.migrationpolicy.org/sites/default/files/publications/ResettlementPeerSupport -FinalWeb.pdf

Beiser, Morton. 2003. "Sponsorship and Resettlement Success.” Journal of International Migration and Integration 4 (2): 203-215.

Bevelander, Pieter. 2016. "Integrating Refugees into Labor Markets: Economic Integration of Refugees into their Host Country is Important and Benefits Both Parties." IZA World of Labor 269: 1-9.

Bevelander, Pieter, and Ravi Pendakur. 2014. "The Labour Market Integration of Refugee and Family Reunion Immigrants: A Comparison of Outcomes in Canada and Sweden." Journal of Ethnic and Migration Studies 40 (5): 689-709.

Bruno, Andorra. 2011. US Refugee Resettlement Assistance. Washington, DC: Congressional Research Service. https://fas.org/sgp/crs/row/R41570.pdf

Chui, Tina, and Kelly Tran. 2003. Longitudinal Survey of Immigrants to Canada: Progress and Challenges of New Immigrants in the Workforce, 2003. Ottawa: Statistics Canada, Social and Aboriginal Statistics Division. https://www150.statcan.gc.ca/n1/en/pub/89-615-x/89615-x2005001-eng.pdf?st=KVNVLjSr 
Citizenship and Immigration Canada (CIC). 2011. Evaluation of Government Assisted Refugees (GAR) and Resettlement Assistance Program (RAP). Ottawa: Evaluation Division, Research and Evaluation. https:/www.canada.ca/content/dam/ircc/migration/ircc/english/pdf/pub/gar-rap.pdf

Constant, Amelie, and Klaus F. Zimmermann. 2005a. "Immigrant Performance and Selective Immigration Policy: A European Perspective." National Institute Economic Review 194 (1): 94-105.

Constant, Amelie F., and Klaus F. Zimmermann. 2005b. "Legal Status at Entry, Economic Performance, and Self-Employment Proclivity: A Bi-National Study of Immigrants." IZA Discussion Paper No. 1910. http://hdl.handle.net/10419/33352

Creese, Gillian, and Brandy Wiebe. 2012. "'Survival Employment': Gender and Deskilling among African Immigrants in Canada." International Migration 50(5): 56-76.

DeVoretz, Don, Sergiy Pivnenko, and Morton Beiser. 2004. "The Economic Experiences of Refugees in Canada." IZA Discussion Paper Series No.1088: 1-31. http://hdl.handle.net/10419/20323

Dhital, Dikshya. 2015. "The Economic Outcomes of Government Assisted Refugees, Privately Sponsored Refugees and Asylum Seekers in Canada." Major Research Paper, Graduate School of Public and International Affairs, University of Ottawa.

European Commission. 2018. Study on the Feasibility and Added Value of Sponsorship Schemes as a Possible Pathway to Safe Channels for Admission to the EU, Including Resettlement: Final Report. European Union, Luxembourg: Publications Office of the European Union. http://www.europeanmigrationlaw.eu/documents/Sponsorship-schemes.pdf 
Evra, Rose and Elena Prokopenko. 2018. Longitudinal Immigration Database (IMDB) Technical Report, 2016. Analytical Studies: Methods and References, Statistics Canada. https://www150.statcan.gc.ca/n1/pub/11-633-x/11-633-x2018019-eng.pdf

https://ruor.uottawa.ca/bitstream/10393/32311/1/DIKSHYA,\%20Dikshya\%2020151.pdf

Fratzke, Susan and Hanne Beirens. 2018. "Three Things the European Union Can Do to Support Private Sponsorship for Refugees." Commentaries. Brussels: Migration Policy Institute Europe. https://www.migrationpolicy.org/news/three-things-european-union-can-dosupport-private-sponsorship-refugees

Fratzke, Susan. 2017. Engaging Communities in Refugee Protection: The Potential of Private Sponsorship in Europe. Brussels: Migration Policy Institute Europe. https://www.migrationpolicy.org/sites/default/files/publications/PrivateSponsorshipEurop e-Fratzke_FINALWEB.pdf

Hiebert, Daniel. 2009. The Economic Integration of Immigrants in Metropolitan Vancouver IRPP Choices 15 (7). Montreal: Institute for Research on Public Policy. http://irpp.org/wp-content/uploads/assets/research/diversity-immigration-andintegration/the-economic-integration-of-immigrants-in-metropolitanvancouver/vol15no7.pdf

Hou, Feng, and Aneta Bonikowska. 2016. "Selections before the Selection: Earnings Advantages of Immigrants Who Were Former Skilled Temporary Foreign Workers in Canada.” International Migration Review. doi:10.1111/imre.12310

Houle, René. 2019. Results from the 2016 Census: Syrian Refugees who Resettled in Canada in 2015 and 2016. Insights on Canadian Society. Ottawa: Statistics Canada. 
https://www150.statcan.gc.ca/n1/en/pub/75-006-x/2019001/article/00001-

eng.pdf?st=kto-D201

Hyndman, Jennifer. 2011. Research Summary on Resettled Refugee Integration in Canada. Ottawa: UN High Commissioner for Refugees (UNHCR). https://www.unhcr.ca/wpcontent/uploads/2014/10/RPT-2011-02-resettled-refugee-e.pdf

Hyndman, Jennifer, William Payne, and Shauna Jimenez. 2017. The State of Private Refugee Sponsorship in Canada: Trends, Issues, and Impacts. Toronto: Centre for Refugee Studies, Refugee Research Network. http://refugeeresearch.net/wpcontent/uploads/2017/02/hyndman_feb\%E2\%80\%9917.pdf

Hynie, Michaela, Ashley Korn, and Dan Tao. 2016. "Social Context and Integration for Government Assisted Refugees in Ontario, Canada." In After the Flight: The Dynamics of Refugee Settlement and Integration, edited by Shiva Nourpanah and Morgan Poteet, 183227. Newcastle Upon Tyne: Cambridge Scholars.

Immigration, Refugees and Citizenship Canada (IRCC). 2016. Evaluation of the Resettlement Programs (GAR, PSR, BVOR and RAP). Ottawa: Immigration, Refugees and Citizenship Canada.

https://www.canada.ca/content/dam/ircc/migration/ircc/english/pdf/pub/resettlement.pdf

Jedwab, Jack. 2018. "GARs vs. PSRs: Explaining Differences in Outcomes for Recent Refugees to Canada." Canadian Diversity 15 (2): 38-46.

Korn, Ashley and Philippe Raphael. 2016. "Employment Pathways for Refugees: An Approach for Overcoming Barriers for Government-Assisted Refugees in Ontario.” Canadian Diversity 13 (2): 36-40. 
Krahn, Harvey, Tracey Derwing, Marlene Mulder, and Lori Wilkinson. 2000. "Educated and Underemployed: Refugee Integration into the Canadian Labour Market." Journal of International Migration and Integration 1 (1): 59-84.

Kumin, Judith. 2015. Welcoming Engagement: How Private Sponsorship Can Strengthen Refugee Resettlement in the European Union. Brussels: Migration Policy Institute Europe. https://www.migrationpolicy.org/sites/default/files/publications/AsylumPrivateSponsorship-Kumin-FINAL.pdf

Labman, Shauna. 2016. "Private Sponsorship: Complementary or Conflicting Interests?" Refuge 32 (2): 67-80. https://refuge.journals.yorku.ca/index.php/refuge/article/view/40266/36411 Lanphier, Michael. 2003. "Sponsorship: Organizational, Sponsor, and Refugee Perspectives." Journal of International Migration and Integration 4 (2): 237-56.

Lenard, Patti Tamara. 2016. "Resettling Refugees: Is Private Sponsorship a Just Way Forward?" Journal of Global Ethics 12 (3): 300-310.

Levitz, Stephanie. 2016. "Study: Iraqi Refugees Who Came in Harper Years Fared Worse than Others." The Globe and Mail, August 14. https://www.theglobeandmail.com/news/national/study-iraqi-refugees-who-came-inharper-years-fared-worse-than-others/article31400482/

Macklin, Audrey, Kathryn Barber, Luin Goldring, Jennifer Hyndman, Anna Korteweg, Shauna Labman, and Jona Zyfi. 2018. "A Preliminary Investigation into Private Refugee Sponsors." Canadian Ethnic Studies 50 (2): 35-57.

Mata, Fernando, and Ravi Pendakur. 2017. "Of Intake and Outcomes: Wage Trajectories of Immigrant Classes in Canada." Journal of International Migration and Integration 18 (3): $829-44$. 
Nakhaie, M. Reza. 2018. "Service Needs of Immigrants and Refugees." Journal of International Migration and Integration 19 (1): 143-60.

Neupane, Dhruba Raj. 2012. "Finding a New Job in a New Home: The Labour Market Experiences of Government Assisted Refugees in Canada." Major Research Paper, Immigration and Settlement Studies, Ryerson University. https://digital.library.ryerson.ca/islandora/object/RULA\%3A1510/datastream/OBJ/view

Oda, Anna, Michaela Hynie, Andrew Tuck, Branka Agic, Brenda Roche, and Kwame McKenzie. 2018. "Differences in Self-Reported Health and Unmet Health Needs Between Government Assisted and Privately Sponsored Syrian Refugees: A CrossSectional Survey." Journal of Immigrant and Minority Health.

Picot, Garnett, and Feng Hou. 2011. "Divergent Trends in Citizenship Rates among Immigrants in Canada and the United States." Analytical Studies Branch Research Paper Series 338. Ottawa: Statistics Canada. https://www150.statcan.gc.ca/n1/en/pub/11 f0019m/11 f0019m2011338-eng.pdf?st=2kZO40d

Picot, Garnett, Yan Zhang, and Feng Hou. 2019. Labour Market Outcomes among Refugees to Canada. Analytical Studies Branch Research Paper Series 419. Ottawa: Statistics Canada. https://www150.statcan.gc.ca/n1/en/pub/11f0019m/11f0019m2019007eng.pdf?st=GgxIs5jF

Portes, Alejandro, and Rubén G Rumbaut. 2001. Legacies: The Story of the Immigrant Second Generation. Berkeley: University of California Press. 
Sweetman, Arthur, and Casey Warman. 2013. "Canada's Immigration Selection System and Labour Market Outcomes." Canadian Public Policy 39 (s1): 141-164.

Treviranus, Barbara, and Michael Casasola. 2003. "Canada’s Private Sponsorship of Refugees Program: A Practitioners Perspective of Its Past and Future." Journal of International Migration and Integration 4 (2): 177-202.

van Selm, Joanne. 2003. "Public-Private Partnerships in Refugee Resettlement: Europe and the US." Journal of International Migration and Integration 4 (2): 157-175.

Vertovec, Steven. 2007. "Super-diversity and Its Implications." Ethnic and Racial Studies 30 (6): 1024-54.

Wilkinson, Lori, and Joseph Garcea. 2017. The Economic Integration of Refugees in Canada: A Mixed Record? Washington, DC: Migration Policy Institute. https://www.migrationpolicy.org/sites/default/files/publications/TCM-Asylum_CanadaFINAL.pdf

Woon, Yuen-Fong. 1987. "The Mode of Refugee Sponsorship and the Socio-Economic Adaptation of Vietnamese in Victoria: A Three-Year Perspective." In Uprooting, Loss and Adaptation: The Resettlement of Indochinese in Canada, edited by Kwok B. Chan and Doreen Marie Indra, 132-146. Ottawa: Canada Public Health Association.

Yu, Soinjin, and Colleen Dempsey. 2004. "Refugees to Canada: Who Are They and How They Faring?" Canadian Issues 5: 5-9. 


\section{Figures}

Figure 1. Observed employment rates of immigrant/ refugee men and women, by admission category and year since landing.

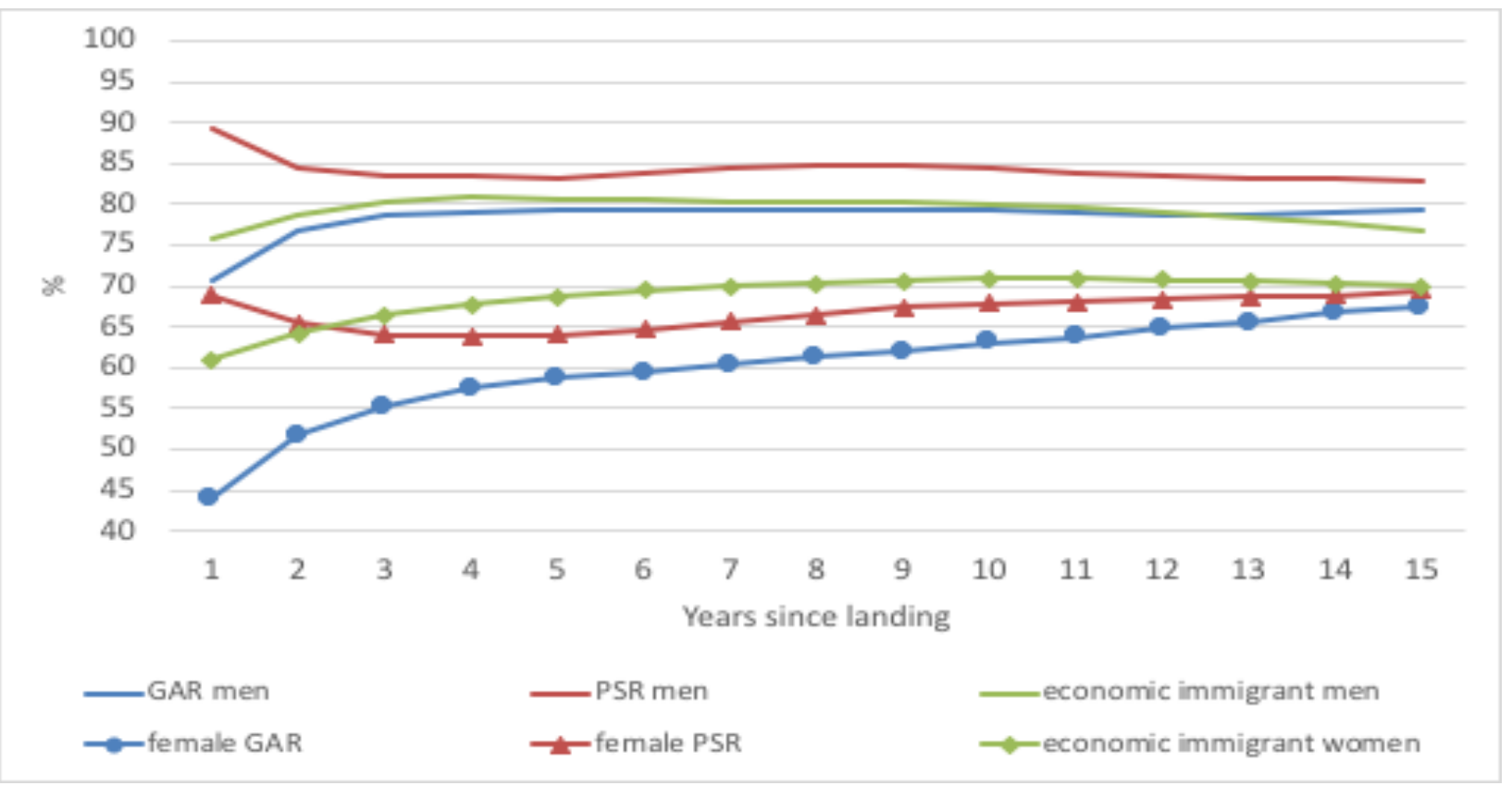

Figure 2. Observed earnings of immigrant/ refugee men and women by admission category and years since landing.

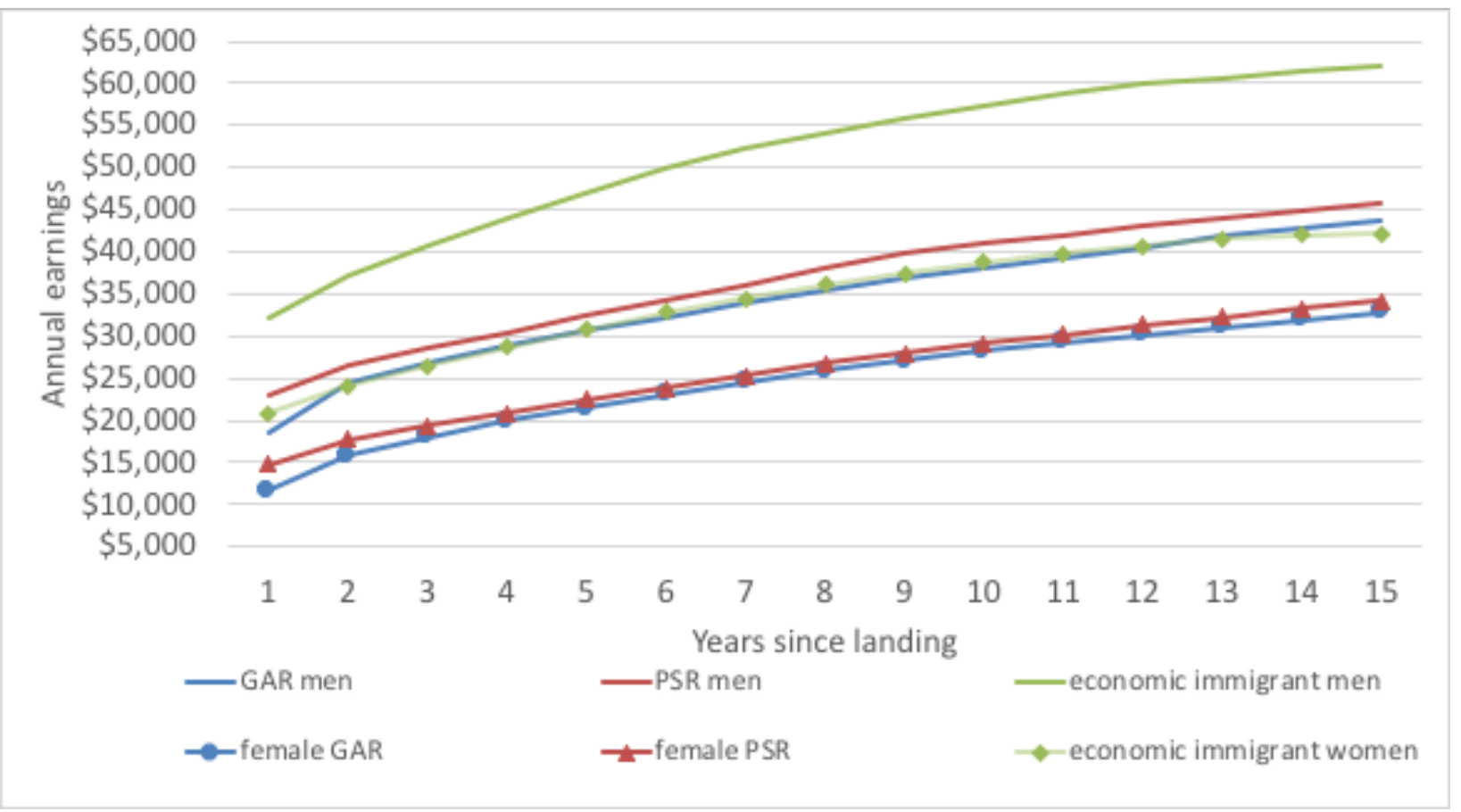


Figure 3 Estimated differences in probability of employment for Privately Sponsored Refugees relative to Government-Assisted Refugees.

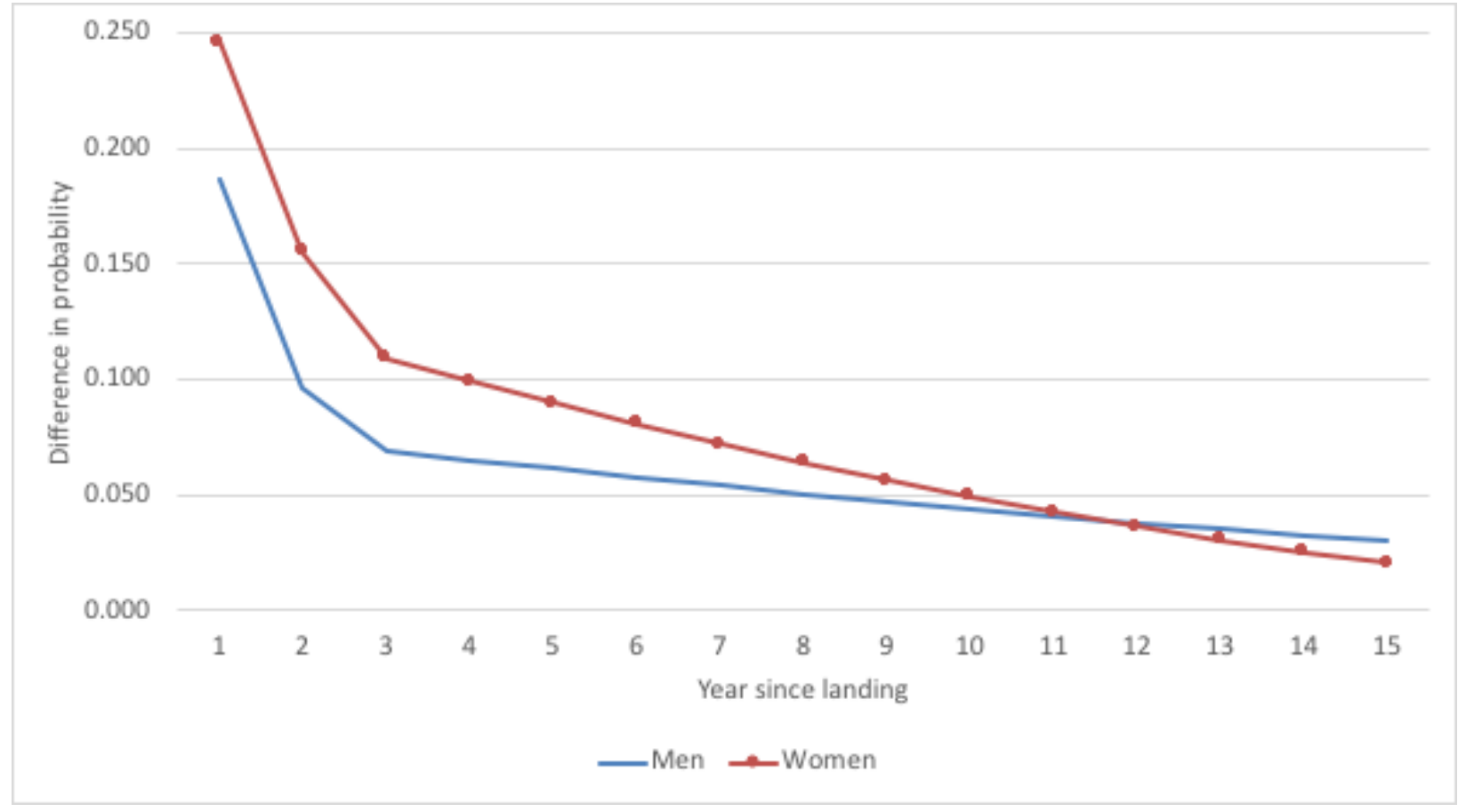

Figure 4 Estimated differences in logged earnings for Privately Sponsored Refugees relative to Government-Assisted Refugees.

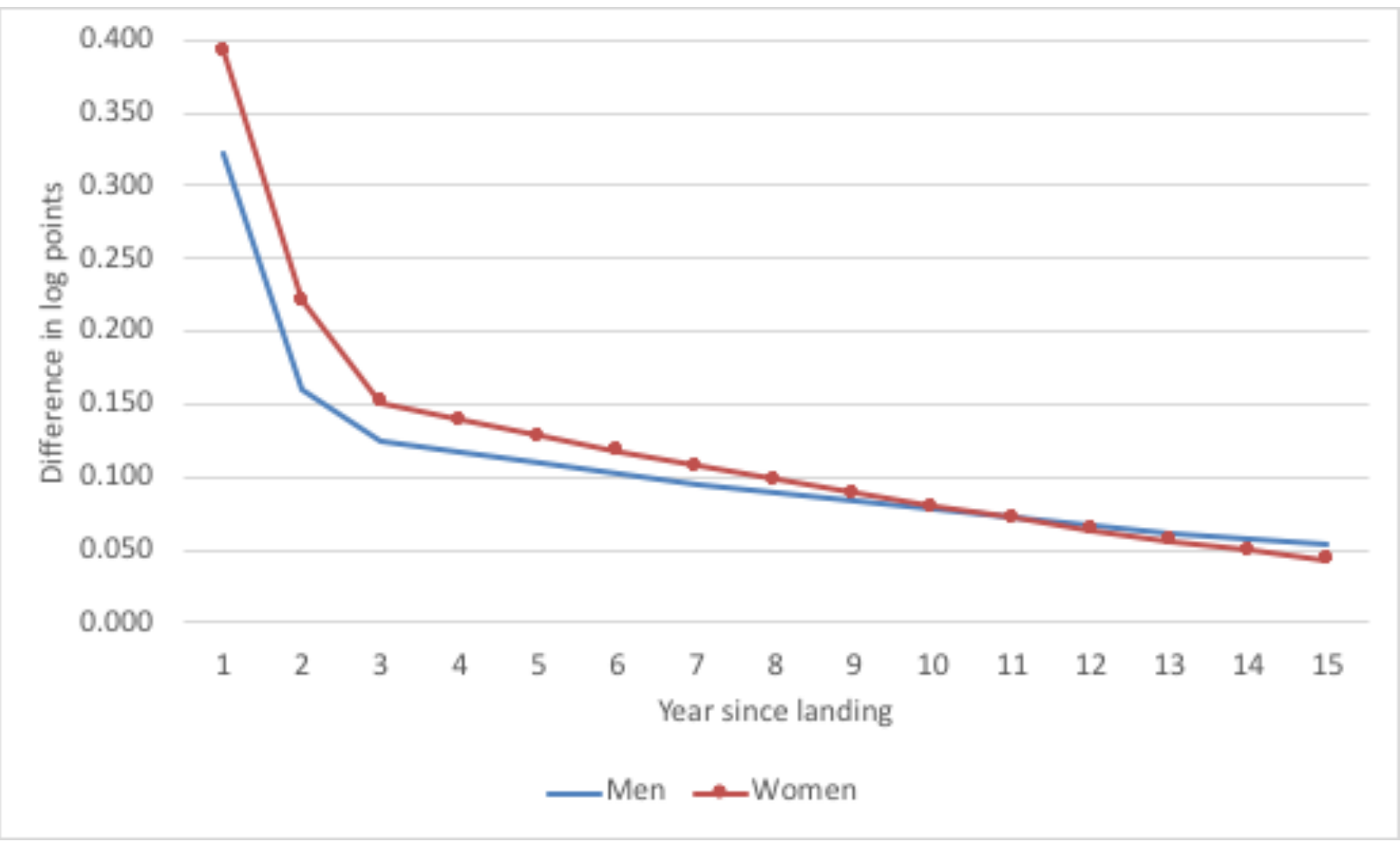


Figure 5 Estimated difference in probability of employment for Privately Sponsored Refugee men relative to Government-Assisted Refugee men by initial level of education.

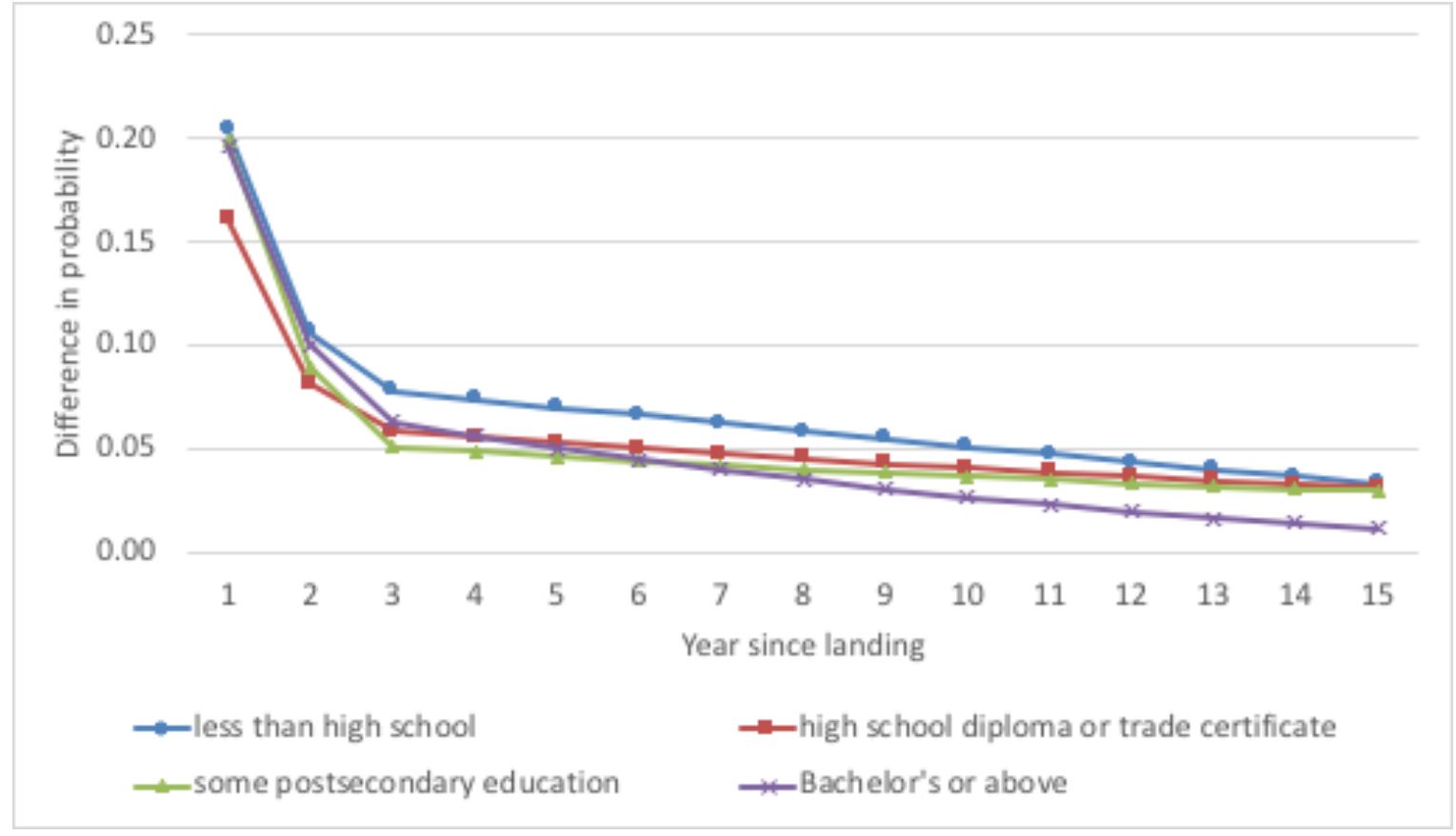

Figure 6 Estimated difference in probability of earning positive employment income for Privately Sponsored Refugee women relative to Government-Assisted Refugee women by initial level of education.

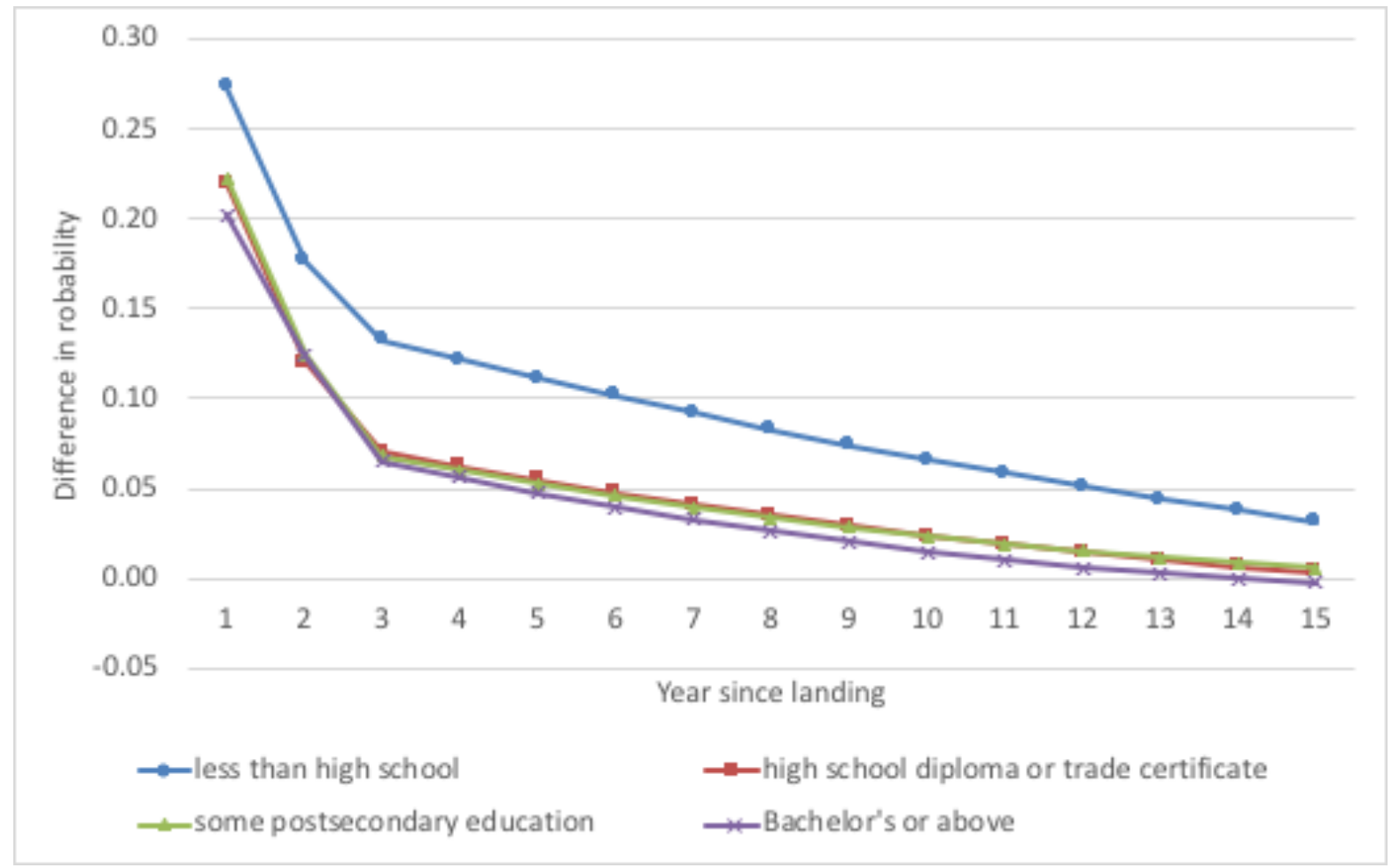


Figure 7. Estimated differences in logged earnings for Privately Sponsored Refugee men relative to Government-Assisted Refugee men by initial level of education.

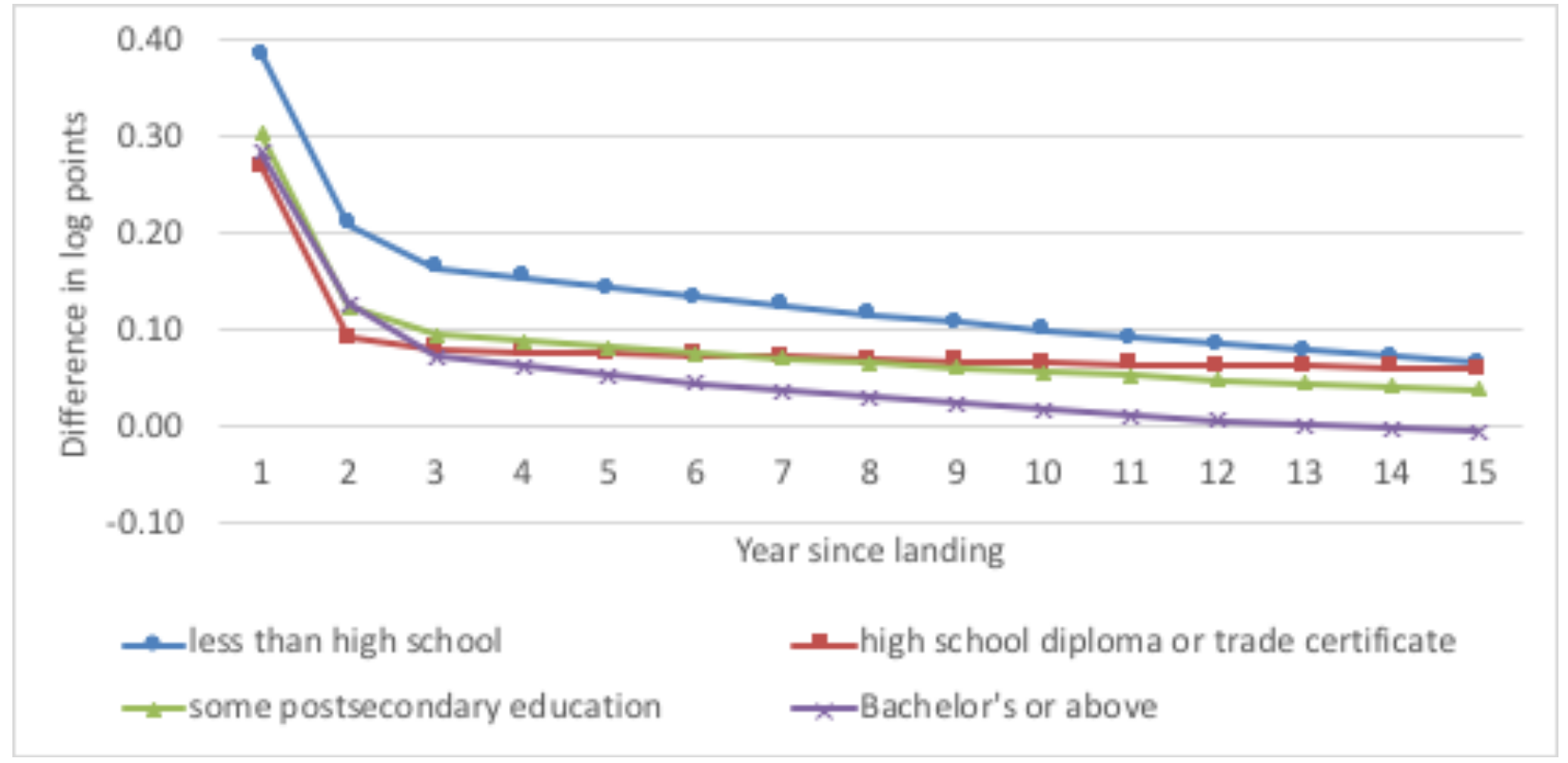

Figure 8. Estimated difference in logged employment income of Privately Sponsored Refugee women relative to Government-Assisted Refugee women by level of education at landing.

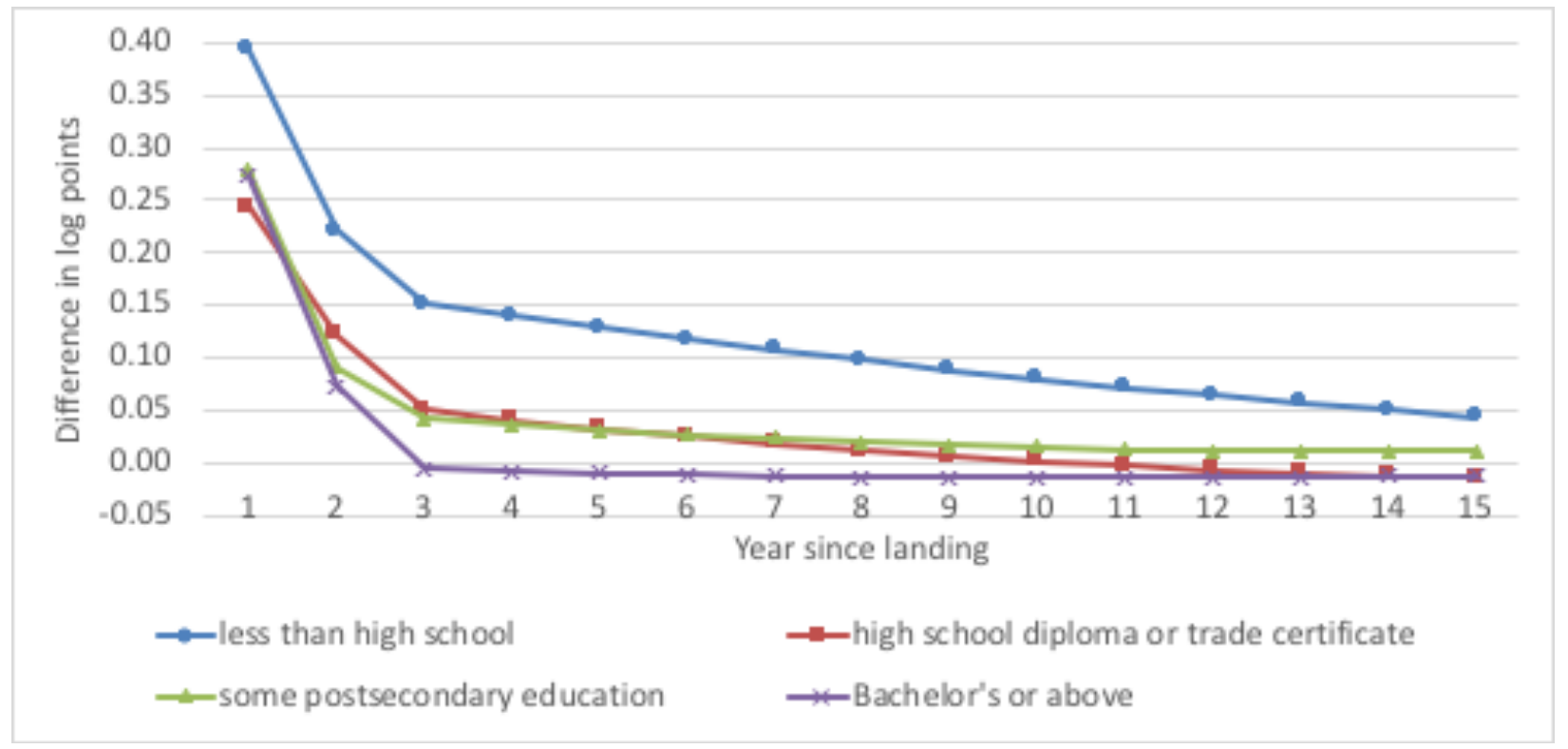


Tables

Table 1. Descriptive statistics of Government-Assisted Refugees and Privately Sponsored

Refugees in year 1 by gender.

\begin{tabular}{|c|c|c|c|c|c|c|}
\hline & \multicolumn{3}{|c|}{ Men } & \multicolumn{3}{|c|}{ Women } \\
\hline & GAR & PSR & Total & GAR & PSR & Total \\
\hline Variables & $\times \quad(1)$ & $\div \quad(2)$ & $(3)$ & $\times \quad(4)$ & $(5)$ & $(6)$ \\
\hline $\mathrm{Ns}$ & 98,360 & 66,520 & 164,880 & 69,952 & 49,002 & 118,954 \\
\hline World region & $\%$ & $\%$ & $\%$ & $\%$ & $\%$ & $\%$ \\
\hline South and Central America, Caribbean & 13.7 & 1.8 & 8.9 & 16.9 & 2.6 & 11.0 \\
\hline Eastern Europe & 23.7 & 43.1 & 31.5 & 23.5 & 38.9 & 29.8 \\
\hline Southern Europe & 6.1 & 1.7 & 4.3 & 8.2 & 2.3 & 5.8 \\
\hline Africa & 14.9 & 15.0 & 14.9 & 13.5 & 13.9 & 13.6 \\
\hline Middle East, West Central Asia & 17.2 & 15.0 & 16.3 & 16.8 & 17.5 & 17.1 \\
\hline Southeast Asia & 22.5 & 22.1 & 22.4 & 19.7 & 23.8 & 21.4 \\
\hline Other Asia & 1.9 & 1.2 & 1.6 & 1.4 & 1.1 & 1.3 \\
\hline \multicolumn{7}{|l|}{ Highest level of education at landing } \\
\hline Less than high school & 53.0 & 48.3 & 51.1 & 63.3 & 58.3 & 61.3 \\
\hline High school competion or trade & 26.8 & 29.7 & 28.0 & 19.4 & 22.4 & 20.7 \\
\hline Some post-secondary & 6.8 & 8.6 & 7.5 & 7.0 & 8.2 & 7.5 \\
\hline Bachelor's degree or higher & 13.4 & 13.4 & 13.4 & 10.2 & 11.1 & 10.6 \\
\hline \multicolumn{7}{|l|}{ Knowledge of official language } \\
\hline English and/or French & 30.9 & 29.9 & 30.5 & 22.0 & 23.5 & 22.6 \\
\hline Neither English nor French & 69.1 & 70.1 & 69.5 & 78.0 & 76.5 & 77.4 \\
\hline \multicolumn{7}{|l|}{ Age at arrival } \\
\hline $20-29$ & 50.3 & 49.8 & 50.1 & 49.1 & 50.7 & 49.7 \\
\hline $30-39$ & 34.7 & 35.3 & 34.9 & 34.9 & 33.0 & 34.1 \\
\hline $40-49$ & 12.8 & 12.3 & 12.6 & 13.3 & 12.9 & 13.2 \\
\hline $50-54$ & 2.2 & 2.6 & 2.4 & 2.7 & 3.4 & 3.0 \\
\hline \multicolumn{7}{|l|}{ Year of landing } \\
\hline $1980-84$ & 23.2 & 16.1 & 20.3 & 19.9 & 17.2 & 18.8 \\
\hline $1985-89$ & 28.3 & 29.1 & 28.6 & 22.8 & 26.3 & 24.3 \\
\hline $1990-94$ & 15.6 & 33.1 & 22.7 & 15.3 & 30.5 & 21.6 \\
\hline 1995-99 & 12.9 & 5.9 & 10.1 & 14.6 & 7.3 & 11.6 \\
\hline $2000-2004$ & 11.2 & 7.1 & 9.6 & 14.3 & 8.6 & 12.0 \\
\hline $2005-2009$ & 8.8 & 8.7 & 8.8 & 12.9 & 10.1 & 11.7 \\
\hline \multicolumn{7}{|l|}{ Place of residence at tax filing time, Year 1} \\
\hline Montreal & 8.5 & 6.9 & 7.9 & 8.6 & 7.5 & 8.1 \\
\hline Toronto & 26.6 & 41.2 & 32.5 & 24.0 & 39.1 & 30.2 \\
\hline Vancouver & 9.7 & 6.4 & 8.4 & 10.3 & 6.7 & 8.8 \\
\hline Ottawa, Calgary, Edmonton, Hamilton, Winnipeg, Quebec City & 28.1 & 23.6 & 26.3 & 28.9 & 24.1 & 26.9 \\
\hline Other small Census Metropoliran Areas & 15.8 & 12.5 & 14.5 & 17.3 & 12.8 & 15.4 \\
\hline Small urban or rural areas & 8.6 & 8.0 & 8.4 & 8.7 & 7.8 & 8.3 \\
\hline No CMA information & 2.6 & 1.3 & 2.1 & 2.2 & 2.1 & 2.2 \\
\hline Mean unemployment rates of males $25-54$ of the province in year 1 & 7.0 & 7.3 & 7.1 & 7.1 & 7.3 & 7.1 \\
\hline Mean \# of months in full-time school in year 1 & 0.3 & 0.3 & 0.3 & 0.2 & 0.3 & 0.2 \\
\hline \multicolumn{7}{|l|}{ Note:The percetages may not add up to 100 due to rounding errors. } \\
\hline Source: Statistics Canada, Longitudinal Immigrant Database. & & & & & & \\
\hline
\end{tabular}




\section{Appendices}

Table A1. Linear probability models predicting the probability of employment for 1982-2015 for refugee men and women who landed at age 20-54 in 1980-2009.

\begin{tabular}{|c|c|c|c|c|c|c|c|c|c|c|c|c|}
\hline & \multicolumn{6}{|c|}{ Men } & \multicolumn{6}{|c|}{ Women } \\
\hline & \multicolumn{3}{|c|}{ Model 1} & \multicolumn{3}{|c|}{ Model 2} & \multicolumn{3}{|c|}{ Model 1} & \multicolumn{3}{|c|}{ Model 2} \\
\hline & coeff & SE & & coeff & SE & & coeff & SE & & coeff & SE & \\
\hline Privately sponsored refugee (PSR) & 0.082 & 0.003 & $* * *$ & 0.079 & 0.008 & $* * *$ & 0.142 & 0.004 & $* * *$ & 0.125 & 0.012 & $* * *$ \\
\hline Government Assisted Refugee (GAR) & (rg) & & & (rg) & & & (rg) & & & $(\mathrm{rg})$ & & \\
\hline Year 1 & -0.012 & 0.003 & $* * *$ & 0.007 & 0.006 & (ns) & -0.046 & 0.005 & $* * *$ & -0.066 & 0.010 & *** \\
\hline Year 2 & -0.004 & 0.002 & (ns) & 0.012 & 0.005 & * & -0.005 & 0.004 & (ns) & -0.021 & 0.008 & $*$ \\
\hline Years since landing (Year 3+) & -0.005 & 0.000 & $* * *$ & 0.003 & 0.001 & $* *$ & 0.001 & 0.001 & $* *$ & 0.007 & 0.001 & $* * *$ \\
\hline Squared years since landing (Year $3+$ ) & 0.000 & 0.000 & $* * *$ & 0.000 & 0.000 & $* * *$ & 0.000 & 0.000 & $* * *$ & -0.001 & 0.000 & $* * *$ \\
\hline \multicolumn{13}{|l|}{ Highest level of education at landing } \\
\hline Less than high school & -0.061 & 0.002 & $* * *$ & -0.024 & 0.005 & $* * *$ & -0.113 & 0.003 & $* * *$ & -0.118 & 0.008 & $* * *$ \\
\hline High school competion or trade & -0.031 & 0.002 & $* * *$ & -0.010 & 0.005 & (ns) & -0.044 & 0.003 & $* * *$ & -0.016 & 0.009 & (ns) \\
\hline Some post-secondary & -0.028 & 0.003 & $* * *$ & 0.000 & 0.008 & (ns) & -0.026 & 0.004 & $* * *$ & -0.017 & 0.011 & (ns) \\
\hline Bachelor's or higher degree & (rg) & & & (rg) & & & (rg) & & & (rg) & & \\
\hline \multicolumn{13}{|l|}{ Knowledge of official language } \\
\hline English and/or French & (rg) & & & (rg) & & & -0.062 & 0.002 & $* * *$ & -0.064 & 0.006 & $* * *$ \\
\hline Neither English nor French & -0.026 & 0.001 & $* * *$ & -0.030 & 0.004 & $* * *$ & (rg) & & & $(\mathrm{rg})$ & & \\
\hline PSR interacted with Year 1 & 0.105 & 0.003 & $* * *$ & 0.082 & 0.008 & $* * *$ & 0.104 & 0.004 & $* * *$ & 0.061 & 0.013 & $* * *$ \\
\hline PSR interacted with Year 2 & 0.014 & 0.003 & $* * *$ & 0.009 & 0.008 & (ns) & 0.014 & 0.004 & $* * *$ & 0.001 & 0.012 & (ns) \\
\hline PSR interacted with YSL & -0.004 & 0.000 & $* * *$ & -0.007 & 0.001 & $* * *$ & -0.012 & 0.001 & $* * *$ & -0.015 & 0.002 & $* * *$ \\
\hline PSR interacted with squared YSL & 0.000 & 0.000 & $* * *$ & 0.000 & 0.000 & $* * *$ & 0.000 & 0.000 & $* * *$ & 0.000 & 0.000 & *** \\
\hline Less than HS interacted with Year 1 & & & & 0.019 & 0.006 & ** & & & & 0.081 & 0.009 & $* * *$ \\
\hline High school competion or trade interacted with Year 1 & & & & 0.035 & 0.006 & *** & & & & 0.027 & 0.010 & $* *$ \\
\hline Some post-secondary interacted with Year 1 & & & & 0.003 & 0.009 & (ns) & & & & 0.035 & 0.012 & $* *$ \\
\hline Less than HS interacted with Year 2 & & & & -0.001 & 0.005 & (ns) & & & & 0.048 & 0.008 & $* * *$ \\
\hline High school competion or trade interacted with Year 2 & & & & 0.008 & 0.006 & (ns) & & & & 0.021 & 0.009 & $*$ \\
\hline Some post-secondary interacted with Year 2 & & & & -0.005 & 0.008 & (ns) & & & & 0.026 & 0.011 & $*$ \\
\hline Less than HS interacted with YSL & & & & -0.011 & 0.001 & $* * *$ & & & & -0.007 & 0.001 & $* * *$ \\
\hline High school competion or trade interacted with YSL & & & & -0.007 & 0.001 & $* * *$ & & & & -0.008 & 0.001 & $* * *$ \\
\hline Some post-secondary interacted with YSL & & & & -0.006 & 0.001 & *** & & & & -0.003 & 0.002 & $*$ \\
\hline Less than HS interacted with squared YSL & & & & 0.000 & 0.000 & *** & & & & 0.000 & 0.000 & *** \\
\hline High school competion or trade interacted with squared YSL & & & & 0.000 & 0.000 & $* * *$ & & & & 0.000 & 0.000 & $* * *$ \\
\hline Some post-secondary interacted with squared YSL & & & & 0.000 & 0.000 & $* * *$ & & & & 0.000 & 0.000 & $*$ \\
\hline PSR interacted with less than high school & & & & 0.007 & 0.008 & (ns) & & & & 0.072 & 0.012 & *** \\
\hline PSR interacted with HS completion/trade & & & & -0.017 & 0.009 & (ns) & & & & 0.001 & 0.014 & (ns) \\
\hline PSR interacted with some post-secondary & & & & -0.025 & 0.012 & $*$ & & & & -0.002 & 0.017 & (ns) \\
\hline Neither English nor French interacted with Year 1 & & & & -0.049 & 0.004 & $* * *$ & & & & -0.042 & 0.006 & $* * *$ \\
\hline Neither English nor French interacted with Year 2 & & & & -0.022 & 0.004 & *** & & & & -0.024 & 0.006 & $* * *$ \\
\hline Neither English nor French interacted with YSL & & & & 0.001 & 0.001 & * & & & & 0.001 & 0.001 & (ns) \\
\hline Neither English nor French interacted with squared YSL & & & & 0.000 & 0.000 & * & & & & 0.000 & 0.000 & (ns) \\
\hline PSR interacted with Neither English nor French & & & & 0.008 & 0.006 & (ns) & & & & -0.036 & 0.009 & $* * *$ \\
\hline PSR interacted with less than high school interacted with Year 1 & & & & 0.002 & 0.009 & (ns) & & & & 0.000 & 0.013 & (ns) \\
\hline PSR interacted with HS completion/trade interacted with Year 1 & & & & -0.018 & 0.010 & (ns) & & & & 0.016 & 0.015 & (ns) \\
\hline PSR interacted with some post-secondary interacted with Year 1 & & & & 0.028 & 0.013 & * & & & & 0.023 & 0.019 & (ns) \\
\hline PSR interacted with less than high school interacted with Year 2 & & & & -0.001 & 0.008 & (ns) & & & & -0.019 & 0.012 & (ns) \\
\hline PSR interacted with HS completion/ trade interacted with Year 2 & & & & -0.002 & 0.009 & (ns) & & & & -0.005 & 0.013 & (ns) \\
\hline PSR interacted with some post-secondary interacted with Year 2 & & & & 0.014 & 0.012 & (ns) & & & & 0.003 & 0.017 & (ns) \\
\hline PSR interacted with less than high school interacted with YSL & & & & 0.003 & 0.001 & * & & & & -0.001 & 0.002 & (ns) \\
\hline PSR interacted with HS completion/trade interacted with YSL & & & & 0.004 & 0.001 & $* *$ & & & & 0.002 & 0.002 & (ns) \\
\hline PSR interacted with some post-secondary interacted with YSL & & & & 0.005 & 0.002 & ** & & & & 0.002 & 0.003 & (ns) \\
\hline \multicolumn{2}{|l|}{ PSR interacted with less than high school interacted with squared YSL } & & & 0.000 & 0.000 & *** & & & & 0.000 & 0.000 & (ns) \\
\hline \multicolumn{2}{|l|}{ PSR interacted with HS completion/trade interacted with squared YSL } & & & 0.000 & 0.000 & ** & & & & 0.000 & 0.000 & (ns) \\
\hline \multicolumn{2}{|l|}{ PSR interacted with some post-secondary interacted with squared YSL } & & & 0.000 & 0.000 & * & & & & 0.000 & 0.000 & (ns) \\
\hline PSR interacted with Neither English nor French interacted with Ye & & & & 0.041 & 0.006 & *** & & & & 0.056 & 0.010 & *** \\
\hline PSR interacted with Neither English nor French interacted with Ye & & & & 0.011 & 0.006 & (ns) & & & & 0.034 & 0.009 & $* * *$ \\
\hline PSR interacted with Neither English nor French interacted with YSI & & & & -0.001 & 0.001 & (ns) & & & & 0.005 & 0.001 & $* *$ \\
\hline PSR interacted with Neither English nor French interacted with sq & red YSL & & & 0.000 & 0.000 & (ns) & & & & 0.000 & 0.000 & $* *$ \\
\hline Unemployment rate of province of residence & -0.019 & 0.000 & $* * *$ & -0.019 & 0.000 & $* * *$ & -0.022 & 0.000 & $* * *$ & -0.022 & 0.000 & $* * *$ \\
\hline Months of full-time attending school & -0.011 & 0.000 & $* * *$ & -0.011 & 0.000 & $* * *$ & 0.000 & 0.000 & (ns) & 0.000 & 0.000 & (ns) \\
\hline Age at arrival & & & & & & & & & & & & \\
\hline $20-29$ & (rg) & & & (rg) & & & (rg) & & & $(\mathrm{rg})$ & & \\
\hline $30-39$ & -0.076 & 0.001 & $* * *$ & -0.076 & 0.001 & $* * *$ & -0.064 & 0.002 & $* * *$ & -0.065 & 0.002 & $* * *$ \\
\hline $40-49$ & -0.242 & 0.002 & $* * *$ & -0.242 & 0.002 & $* * *$ & -0.251 & 0.003 & $* * *$ & -0.252 & 0.003 & $* * *$ \\
\hline $50-54$ & -0.494 & 0.005 & $* * *$ & -0.494 & 0.005 & *** & -0.477 & 0.004 & $* * *$ & -0.477 & 0.004 & $* * *$ \\
\hline
\end{tabular}


Table A2. OLS models predicting logged earnings for tax years 1982-2015 for refugee men and women who landed at age 20-54 in 1980-2009.

\begin{tabular}{|c|c|c|c|c|c|c|c|c|c|c|c|c|}
\hline & \multicolumn{6}{|c|}{ Men } & \multicolumn{6}{|c|}{ Women } \\
\hline & \multicolumn{3}{|c|}{ Model 1} & \multicolumn{3}{|c|}{ Model 2} & \multicolumn{3}{|c|}{ Model 1} & \multicolumn{3}{|c|}{ Model 2} \\
\hline & coeff & SE & & coeff & SE & & coeff & SE & & coeff & SE & \\
\hline Privately sponsored refugee (PSR) & 0.150 & 0.006 & *** & 0.101 & 0.020 & *** & 0.130 & 0.008 & *** & -0.035 & 0.028 & $\overline{\text { (ns) }}$ \\
\hline Government Assisted Refugee (GAR) & (rg) & & & (rg) & & & (rg) & & & (rg) & & \\
\hline Year 1 & -0.398 & 0.007 & $* * *$ & -0.333 & 0.016 & $* * *$ & -0.441 & 0.011 & $* * *$ & -0.462 & 0.025 & $* * *$ \\
\hline Year 2 & -0.061 & 0.006 & $* * *$ & -0.030 & 0.014 & * & -0.048 & 0.009 & $* * *$ & -0.053 & 0.022 & * \\
\hline Years since landing (Year 3+) & 0.040 & 0.001 & $* * *$ & 0.064 & 0.002 & $* * *$ & 0.054 & 0.001 & $* * *$ & 0.083 & 0.003 & $* * *$ \\
\hline Squared years since landing (Year $3+$ ) & -0.001 & 0.000 & $* * *$ & -0.002 & 0.000 & $* * *$ & -0.001 & 0.000 & $* * *$ & -0.002 & 0.000 & $* * *$ \\
\hline \multicolumn{13}{|l|}{ Highest level of education at landing } \\
\hline Less than high school & -0.307 & 0.006 & $* * *$ & -0.188 & 0.013 & $* * *$ & -0.370 & 0.008 & $* * *$ & -0.147 & 0.018 & $* * *$ \\
\hline High school competion or trade & -0.228 & 0.006 & $* * *$ & -0.133 & 0.014 & $* * *$ & -0.263 & 0.008 & $* * *$ & -0.144 & 0.020 & *** \\
\hline Some post-secondary & -0.212 & 0.008 & $* * *$ & -0.125 & 0.019 & $* * *$ & -0.198 & 0.010 & $* * *$ & -0.110 & 0.025 & *** \\
\hline Bachelor's or higher degree & (rg) & & & (rg) & & & (rg) & & & (rg) & & \\
\hline \multicolumn{13}{|l|}{ Knowledge of official language } \\
\hline English and/or French & $(\mathrm{rg})$ & & & (rg) & & & (rg) & & & (rg) & & \\
\hline Neither English nor French & -0.133 & 0.004 & $* * *$ & -0.071 & 0.009 & $* * *$ & -0.180 & 0.005 & $* * *$ & -0.163 & 0.014 & $* * *$ \\
\hline PSR interacted with Year 1 & 0.172 & 0.007 & $* * *$ & 0.123 & 0.022 & $* * *$ & 0.193 & 0.010 & $* * *$ & 0.257 & 0.033 & $* * *$ \\
\hline PSR interacted with Year 2 & 0.011 & 0.006 & (ns) & 0.029 & 0.020 & (ns) & 0.043 & 0.009 & $* * *$ & 0.082 & 0.030 & $* *$ \\
\hline PSR interacted with YSL & -0.009 & 0.001 & $* * *$ & -0.009 & 0.003 & $* *$ & -0.011 & 0.001 & $* * *$ & 0.004 & 0.004 & (ns) \\
\hline PSR interacted with squared YSL & 0.000 & 0.000 & $* * *$ & 0.000 & 0.000 & $*$ & 0.000 & 0.000 & $* * *$ & 0.000 & 0.000 & (ns) \\
\hline Less than HS interacted with Year 1 & & & & 0.051 & 0.016 & $* *$ & & & & 0.126 & 0.024 & $* * *$ \\
\hline High school competion or trade interacted with Year 1 & & & & 0.078 & 0.017 & $* * *$ & & & & 0.136 & 0.026 & $* * *$ \\
\hline Some post-secondary interacted with Year 1 & & & & 0.042 & 0.023 & (ns) & & & & 0.087 & 0.032 & $* *$ \\
\hline Less than HS interacted with Year 2 & & & & -0.007 & 0.014 & (ns) & & & & 0.007 & 0.021 & (ns) \\
\hline High school competion or trade interacted with Year 2 & & & & 0.021 & 0.015 & (ns) & & & & 0.023 & 0.023 & (ns) \\
\hline Some post-secondary interacted with Year 2 & & & & 0.023 & 0.021 & (ns) & & & & 0.048 & 0.028 & (ns) \\
\hline Less than HS interacted with YSL & & & & -0.025 & 0.002 & $* * *$ & & & & -0.040 & 0.003 & $* * *$ \\
\hline High school competion or trade interacted with YSL & & & & -0.018 & 0.002 & $* * *$ & & & & -0.020 & 0.003 & $* * *$ \\
\hline Some post-secondary interacted with YSL & & & & -0.014 & 0.003 & $* * *$ & & & & -0.016 & 0.004 & $* * *$ \\
\hline Less than HS interacted with squared YSL & & & & 0.001 & 0.000 & $* * *$ & & & & 0.001 & 0.000 & $* * *$ \\
\hline High school competion or trade interacted with squared YSL & & & & 0.000 & 0.000 & $* * *$ & & & & 0.001 & 0.000 & $* * *$ \\
\hline Some post-secondary interacted with squared YSL & & & & 0.000 & 0.000 & $* *$ & & & & 0.000 & 0.000 & $* * *$ \\
\hline PSR interacted with less than high school & & & & 0.095 & 0.021 & $* * *$ & & & & 0.187 & 0.029 & $* * *$ \\
\hline PSR interacted with HS completion/trade & & & & -0.016 & 0.022 & (ns) & & & & 0.079 & 0.031 & * \\
\hline PSR interacted with some post-secondary & & & & 0.012 & 0.029 & (ns) & & & & 0.059 & 0.038 & (ns) \\
\hline Neither English nor French interacted with Year 1 & & & & -0.144 & 0.010 & $* * *$ & & & & -0.086 & 0.017 & $* * *$ \\
\hline Neither English nor French interacted with Year 2 & & & & -0.042 & 0.010 & $* * *$ & & & & -0.009 & 0.015 & (ns) \\
\hline Neither English nor French interacted with YSL & & & & -0.006 & 0.001 & $* * *$ & & & & 0.002 & 0.002 & (ns) \\
\hline Neither English nor French interacted with squared YSL & & & & 0.000 & 0.000 & * & & & & 0.000 & 0.000 & * \\
\hline PSR interacted with Neither English nor French & & & & 0.004 & 0.014 & (ns) & & & & 0.046 & 0.020 & * \\
\hline PSR interacted with less than high school interacted with Year 1 & & & & 0.007 & 0.023 & (ns) & & & & -0.067 & 0.034 & (ns) \\
\hline PSR interacted with HS completion/trade interacted with Year 1 & & & & 0.001 & 0.025 & (ns) & & & & -0.108 & 0.037 & $* *$ \\
\hline PSR interacted with some post-secondary interacted with Year 1 & & & & 0.008 & 0.033 & (ns) & & & & -0.053 & 0.046 & (ns) \\
\hline PSR interacted with less than high school interacted with Year 2 & & & & -0.013 & 0.022 & (ns) & & & & -0.039 & 0.031 & (ns) \\
\hline PSR interacted with HS completion/ trade interacted with Year 2 & & & & -0.019 & 0.023 & (ns) & & & & -0.031 & 0.034 & (ns) \\
\hline PSR interacted with some post-secondary interacted with Year 2 & & & & -0.015 & 0.031 & (ns) & & & & -0.041 & 0.042 & (ns) \\
\hline PSR interacted with less than high school interacted with YSL & & & & -0.001 & 0.003 & (ns) & & & & -0.010 & 0.005 & * \\
\hline PSR interacted with HS completion/trade interacted with YSL & & & & 0.009 & 0.004 & * & & & & -0.008 & 0.005 & (ns) \\
\hline PSR interacted with some post-secondary interacted with YSL & & & & 0.004 & 0.005 & (ns) & & & & -0.004 & 0.006 & (ns) \\
\hline \multicolumn{2}{|l|}{ PSR interacted with less than high school interacted with squared YSL } & & & 0.000 & 0.000 & (ns) & & & & 0.000 & 0.000 & (ns) \\
\hline \multicolumn{2}{|l|}{ PSR interacted with HS completion/trade interacted with squared YSL } & & & 0.000 & 0.000 & (ns) & & & & 0.000 & 0.000 & (ns) \\
\hline \multicolumn{2}{|l|}{ PSR interacted with some post-secondary interacted with squared YSL } & & & 0.000 & 0.000 & (ns) & & & & 0.000 & 0.000 & (ns) \\
\hline PSR interacted with Neither English nor French interacted with Y & $\operatorname{ar} 1$ & & & 0.081 & 0.016 & $* * *$ & & & & 0.018 & 0.024 & (ns) \\
\hline PSR interacted with Neither English nor French interacted with Y & $\operatorname{ar} 2$ & & & -0.007 & 0.015 & (ns) & & & & -0.013 & 0.022 & (ns) \\
\hline PSR interacted with Neither English nor French interacted with $Y$ & & & & -0.003 & 0.002 & (ns) & & & & -0.009 & 0.003 & $* *$ \\
\hline PSR interacted with Neither English nor French interacted with s & Lared YSL & & & 0.000 & 0.000 & (ns) & & & & 0.000 & 0.000 & $*$ \\
\hline Unemployment rate of province of residence & -0.043 & 0.001 & $* * *$ & -0.043 & 0.001 & *** & -0.022 & 0.001 & $* * *$ & -0.022 & 0.001 & $* * *$ \\
\hline Months of full-time attending school & -0.070 & 0.001 & $* * *$ & -0.069 & 0.001 & $* * *$ & -0.059 & 0.001 & $* * *$ & -0.057 & 0.001 & $* * *$ \\
\hline Age at arrival & & & & & & & & & & & & \\
\hline $20-29$ & (rg) & & & (rg) & & & (rg) & & & (rg) & & \\
\hline $30-39$ & -0.063 & 0.004 & $* * *$ & -0.063 & 0.004 & $* * *$ & -0.023 & 0.004 & $* * *$ & -0.025 & 0.004 & $* * *$ \\
\hline $40-49$ & -0.181 & 0.005 & $* * *$ & -0.182 & 0.005 & $* * *$ & -0.119 & 0.007 & $* * *$ & -0.122 & 0.007 & $* * *$ \\
\hline $50-54$ & -0.324 & 0.014 & $* * *$ & -0.323 & 0.014 & $* * *$ & -0.217 & 0.021 & $* * *$ & -0.222 & 0.021 & $* * *$ \\
\hline
\end{tabular}


Table A2. Continued.

\begin{tabular}{|c|c|c|c|c|c|c|c|c|c|c|c|c|}
\hline \multicolumn{13}{|l|}{ Region of birth } \\
\hline South and Central America, Caribbean & -0.166 & 0.006 & $* * *$ & -0.166 & 0.006 & $* * *$ & -0.171 & 0.007 & $* * *$ & -0.169 & 0.007 & $* * *$ \\
\hline Eastern Europe & $(\mathrm{rg})$ & & & $(\mathrm{rg})$ & & & (rg) & & & (rg) & & \\
\hline Southern Europe & 0.094 & 0.009 & $* * *$ & 0.088 & 0.009 & $* * *$ & 0.125 & 0.009 & $* * *$ & 0.118 & 0.009 & $* * *$ \\
\hline Africa & -0.352 & 0.006 & $* * *$ & -0.355 & 0.006 & $* * *$ & -0.116 & 0.007 & $* * *$ & -0.119 & 0.007 & $* * *$ \\
\hline Middle East, West Central Asia & -0.437 & 0.006 & $* * *$ & -0.439 & 0.006 & $* * *$ & -0.314 & 0.008 & $* * *$ & -0.312 & 0.008 & $* * *$ \\
\hline Southeast Asia & -0.154 & 0.005 & $* * *$ & -0.153 & 0.005 & $* * *$ & -0.118 & 0.006 & $* * *$ & -0.114 & 0.006 & $* * *$ \\
\hline Other Asia & -0.253 & 0.014 & $* * *$ & -0.255 & 0.014 & $* * *$ & -0.174 & 0.020 & $* * *$ & -0.178 & 0.020 & $* * *$ \\
\hline \multicolumn{13}{|l|}{ Place of residence at tax filing time } \\
\hline Montreal & -0.139 & 0.007 & *** & -0.140 & 0.007 & $* * *$ & -0.179 & 0.008 & $* * *$ & -0.182 & 0.008 & $* * *$ \\
\hline Toronto & (rg) & & & (rg) & & & (rg) & & & (rg) & & \\
\hline Vancouver & -0.139 & 0.006 & $* * *$ & -0.139 & 0.006 & $* * *$ & -0.116 & 0.007 & $* * *$ & -0.115 & 0.007 & $* * *$ \\
\hline Ottawa, Calgary, Edmonton, Hamilton, Winnipeg, Quebec City & -0.026 & 0.004 & *** & -0.026 & 0.004 & $* * *$ & -0.051 & 0.005 & $* * *$ & -0.052 & 0.005 & $* * *$ \\
\hline Other small CMAs & 0.026 & 0.005 & *** & 0.026 & 0.005 & $* * *$ & -0.064 & 0.006 & $* * *$ & -0.064 & 0.006 & $* * *$ \\
\hline Small urban or rural areas & 0.065 & 0.006 & *** & 0.064 & 0.006 & $* * *$ & -0.049 & 0.008 & $* * *$ & -0.051 & 0.008 & $* * *$ \\
\hline No CMA information & -0.125 & 0.021 & $* * *$ & -0.128 & 0.021 & $* * *$ & -0.185 & 0.028 & $* * *$ & -0.186 & 0.028 & $* * *$ \\
\hline \multicolumn{13}{|l|}{ Year of landing } \\
\hline $1980-84$ & $(\mathrm{rg})$ & & & $(\mathrm{rg})$ & & & (rg) & & & (rg) & & \\
\hline $1985-89$ & -0.134 & 0.008 & $* * *$ & -0.123 & 0.008 & $* * *$ & -0.077 & 0.011 & $* * *$ & -0.053 & 0.011 & $* * *$ \\
\hline $1990-94$ & -0.356 & 0.009 & $* * *$ & -0.329 & 0.009 & $* * *$ & -0.408 & 0.013 & $* * *$ & -0.358 & 0.013 & $* * *$ \\
\hline 1995-99 & -0.304 & 0.013 & *** & -0.285 & 0.013 & $* * *$ & -0.373 & 0.016 & $* * *$ & -0.337 & 0.016 & *** \\
\hline $2000-2004$ & -0.410 & 0.017 & $* * *$ & -0.400 & 0.017 & $* * *$ & -0.462 & 0.022 & $* * *$ & -0.464 & 0.022 & $* * *$ \\
\hline $2005-2009$ & -0.218 & 0.027 & $* * *$ & -0.211 & 0.027 & $* * *$ & -0.296 & 0.037 & $* * *$ & -0.302 & 0.037 & $* * *$ \\
\hline Landed in 1985-89 interacted with Year 1 & 0.160 & 0.009 & *** & 0.139 & 0.009 & $* * *$ & 0.130 & 0.014 & $* * *$ & 0.096 & 0.014 & *** \\
\hline Landed in 1990-94 interacted with Year 1 & 0.103 & 0.011 & *** & 0.074 & 0.011 & $* * *$ & 0.199 & 0.015 & $* * *$ & 0.165 & 0.015 & $* * *$ \\
\hline Landed in 1995-99 interacted with Year 1 & 0.026 & 0.015 & (ns) & 0.005 & 0.015 & (ns) & 0.050 & 0.020 & $*$ & 0.026 & 0.020 & (ns) \\
\hline Landed in 2000-2004 interacted with Year 1 & 0.250 & 0.018 & $* * *$ & 0.216 & 0.018 & $* * *$ & 0.294 & 0.024 & $* * *$ & 0.252 & 0.024 & $* * *$ \\
\hline Landed in 2005-2009 interacted with Year 1 & 0.219 & 0.027 & *** & 0.184 & 0.027 & $* * *$ & 0.265 & 0.038 & $* * *$ & 0.214 & 0.038 & $* * *$ \\
\hline Landed in 1985-89 interacted with Year 2 & 0.056 & 0.008 & *** & 0.051 & 0.008 & $* * *$ & 0.026 & 0.012 & * & 0.023 & 0.012 & $*$ \\
\hline Landed in 1990-94 interacted with Year 2 & 0.082 & 0.009 & *** & 0.074 & 0.010 & $* * *$ & 0.119 & 0.013 & $* * *$ & 0.117 & 0.014 & *** \\
\hline Landed in 1995-99 interacted with Year 2 & 0.092 & 0.013 & *** & 0.084 & 0.013 & $* * *$ & 0.069 & 0.017 & $* * *$ & 0.069 & 0.017 & $* * *$ \\
\hline Landed in 2000-2004 interacted with Year 2 & 0.234 & 0.016 & *** & 0.227 & 0.016 & $* * *$ & 0.226 & 0.021 & $* * *$ & 0.228 & 0.021 & $* * *$ \\
\hline Landed in 2005-2009 interacted with Year 2 & 0.196 & 0.026 & *** & 0.186 & 0.026 & $* * *$ & 0.185 & 0.037 & $* * *$ & 0.187 & 0.037 & $* * *$ \\
\hline Landed in 1985-89 interacted with YSL & 0.003 & 0.001 & $* *$ & 0.002 & 0.001 & (ns) & 0.000 & 0.002 & (ns) & -0.002 & 0.002 & (ns) \\
\hline Landed in 1990-94 interacted with YSL & 0.022 & 0.001 & $* * *$ & 0.019 & 0.001 & $* * *$ & 0.034 & 0.002 & $* * *$ & 0.029 & 0.002 & $* * *$ \\
\hline Landed in 1995-99 interacted with YSL & 0.029 & 0.002 & *** & 0.026 & 0.002 & $* * *$ & 0.050 & 0.003 & $* * *$ & 0.046 & 0.003 & *** \\
\hline Landed in 2000-2004 interacted with YSL & 0.071 & 0.004 & $* * *$ & 0.070 & 0.004 & $* * *$ & 0.075 & 0.005 & $* * *$ & 0.078 & 0.005 & $* * *$ \\
\hline Landed in 2005-2009 interacted with YSL & 0.053 & 0.009 & $* * *$ & 0.053 & 0.009 & $* * *$ & 0.048 & 0.013 & $* * *$ & 0.051 & 0.013 & *** \\
\hline Landed in $1985-89$ interacted with squared YSL & 0.000 & 0.000 & (ns) & 0.000 & 0.000 & (ns) & 0.000 & 0.000 & ** & 0.000 & 0.000 & *** \\
\hline Landed in 1990-94 interacted with squared YSL & -0.001 & 0.000 & *** & -0.001 & 0.000 & $* * *$ & -0.001 & 0.000 & $* * *$ & -0.001 & 0.000 & $* * *$ \\
\hline Landed in 1995-99 interacted with squared YSL & -0.001 & 0.000 & $* * *$ & -0.001 & 0.000 & $* * *$ & -0.002 & 0.000 & $* * *$ & -0.001 & 0.000 & $* * *$ \\
\hline Landed in 2000-2004 interacted with squared YSL & -0.003 & 0.000 & *** & -0.003 & 0.000 & $* * *$ & -0.003 & 0.000 & $* * *$ & -0.003 & 0.000 & $* * *$ \\
\hline Landed in 2005-2009 interacted with squared YSL & -0.003 & 0.001 & *** & -0.003 & 0.001 & $* * *$ & -0.002 & 0.001 & $*$ & -0.003 & 0.001 & * \\
\hline Intercept & 10.856 & 0.009 & *** & 10.709 & 0.015 & $* * *$ & 10.289 & 0.012 & $* * *$ & 10.098 & 0.021 & $* * *$ \\
\hline Number of obs & 2637550 & & & 2637550 & & & 1565625 & & & 1565625 & & \\
\hline R-squared & 0.135 & & & 0.137 & & & 0.151 & & & 0.154 & & \\
\hline \multicolumn{13}{|c|}{${ }^{*} p<.05 ;{ }^{* *} p<0.01 ;{ }^{* * *} p<.001 ;(n s)$ not significant at $p=.05$ level; $(r g)$ reference group } \\
\hline Source: Statistics Canada, Longitudinal Immigration Database. & & & & & & & & & & & & \\
\hline
\end{tabular}


